Article

\title{
Assessment of FSDAF Accuracy on Cotton Yield Estimation Using Different MODIS Products and Landsat Based on the Mixed Degree Index with Different Surroundings
}

\author{
Linghua Meng ${ }^{1,2}$, Huanjun Liu ${ }^{1, *}$, Susan L. Ustin ${ }^{3}$ (1) and Xinle Zhang ${ }^{4}$ \\ 1 Northeast Institute of Geography and Agroecology, Chinese Academy of Sciences, \\ Changchun 130102, China; menglinghua@iga.ac.cn \\ 2 University of Chinese Academy of Sciences, Beijing 100049, China \\ 3 Center for Spatial Technologies and Remote Sensing (CSTARS), Department of Land, Air, \\ and Water Resources, University of California, Davis, CA 95616, USA; slustin@ucdavis.edu \\ 4 School of Information Technology, Jilin Agricultural University, Changchun 130102, China; \\ zhangxinle@gmail.com \\ * Correspondence: liuhuanjun@iga.ac.cn; Tel.: +86-188-4556-5736
}

Citation: Meng, L.; Liu, H.; Ustin, S.L.; Zhang, X. Assessment of FSDAF Accuracy on Cotton Yield Estimation Using Different MODIS Products and Landsat Based on the Mixed Degree Index with Different Surroundings. Sensors 2021, 21, 5184. https:// doi.org/10.3390/s21155184

Received: 10 June 2021

Accepted: 28 July 2021

Published: 30 July 2021

Publisher's Note: MDPI stays neutral with regard to jurisdictional claims in published maps and institutional affiliations.

Copyright: (c) 2021 by the authors. Licensee MDPI, Basel, Switzerland. This article is an open access article distributed under the terms and conditions of the Creative Commons Attribution (CC BY) license (https:// creativecommons.org/licenses/by/ $4.0 /)$.

\begin{abstract}
Research on fusion modeling of high spatial and temporal resolution images typically uses MODIS products at $500 \mathrm{~m}$ and $250 \mathrm{~m}$ resolution with Landsat images at $30 \mathrm{~m}$, but the effect on results of the date of reference images and the 'mixed pixels' nature of moderate-resolution imaging spectroradiometer (MODIS) images are not often considered. In this study, we evaluated those effects using the flexible spatiotemporal data fusion model (FSDAF) to generate fusion images with both high spatial resolution and frequent coverage over three cotton field plots in the San Joaquin Valley of California, USA. Landsat images of different dates (day-of-year (DOY) 174, 206, and 254, representing early, middle, and end stages of the growing season, respectively) were used as reference images in fusion with two MODIS products (MOD09GA and MOD13Q1) to produce new time-series fusion images with improved temporal sampling over that provided by Landsat alone. The impact on the accuracy of yield estimation of the different Landsat reference dates, as well as the degree of mixing of the two MODIS products, were evaluated. A mixed degree index (MDI) was constructed to evaluate the accuracy and time-series fusion results of the different cotton plots, after which the different yield estimation models were compared. The results show the following: (1) there is a strong correlation (above 0.6 ) between cotton yield and both the Normalized Difference Vegetation Index (NDVI) from Landsat $\left(\mathrm{NDVI}_{\mathrm{L} 30}\right)$ and NDVI from the fusion of Landsat with MOD13Q1 (NDVI ${ }_{\mathrm{F} 250}$ ). (2) Use of a mid-season Landsat image as reference for the fusion of MODIS imagery provides a better yield estimation, $14.73 \%$ and $17.26 \%$ higher than reference images from early or late in the season, respectively. (3) The accuracy of the yield estimation model of the three plots is different and relates to the MDI of the plots and the types of surrounding crops. These results can be used as a reference for data fusion for vegetation monitoring using remote sensing at the field scale.
\end{abstract}

Keywords: FSDAF; mixed pixel; cotton growth; field scale; MDI

\section{Introduction}

Time-series data from satellite images with frequent coverage are important for studying land surface dynamics, such as monitoring vegetation phenology [1,2], detecting land cover and land-use change [3], and estimating agriculture intensity [4]. Additionally, accurate spatiotemporal information about the crop condition during the growing season is critical for crop management and yield estimation [5-7]. It is important to be able to estimate crop yields before harvest for food security and commodity trading purposes.

Satellite images with a long return cycle with fine spatial resolution and a short return cycle with coarse resolution can be used for applications that require imagery from the past 
several decades. Data from the moderate resolution imaging spectroradiometer (MODIS) and the National Oceanic and Atmospheric Association (NOAA) advanced very highresolution radiometer (AVHRR) have coverage every 1-2 days, but the spatial resolution is coarse at $250 \mathrm{~m}$ to $1 \mathrm{~km}$. The other type of data have a fine spatial resolution, but the revisit cycle is long. It is difficult to acquire remote sensing (RS) images with both high spatial resolution and frequent coverage due to technical and budget limitations [8]. For example, RS images acquired from the Landsat and SPOT series and Indian remote sensing (IRS) satellites with spatial resolutions from 6 to $30 \mathrm{~m}$ are usually the primary data source for land use/land cover mapping and change detection [9], ecosystem dynamic monitoring [10,11] and biogeochemical parameter estimation [12]. However, these satellites have longer return cycles (e.g., Landsat is $16 \mathrm{~d}$; IRS is $24 \mathrm{~d}$ ) and are subject to frequent cloud contamination and other poor atmospheric conditions [13]. These conditions have limited the application of these satellites in detecting rapid surface changes associated with intra-seasonal ecosystem variations and natural disasters [14]. In contrast, MODIS has a shorter revisit cycle and can provide frequent observations, but the spatial resolution is coarse [15]. As such, MODIS data cannot meet the requirements for surface cover change and ecosystem monitoring at farm and field scales. Thus, the fusion of data from different types of sensors has become a feasible and less costly method to improve the utility of RS data to monitor surface dynamics at the local level [16].

Spatiotemporal data fusion methods of high spatial and temporal resolution images have been developed to blend these two types of satellite images to generate synthesized data with both high spatial resolution and frequent coverage. Among the weighted function-based methods, the spatial and temporal adaptive reflectance fusion model (STARFM) was the first developed [17]. STARFM assumes that changes in reflectance are consistent and comparable at MODIS and Landsat thematic mapper (TM) resolutions and therefore predicts pixel values using a function that gives a higher weight to more pure MODIS pixels based on information from neighboring Landsat TM pixels. Although STARFM is easy to understand and widely used, it still has the following problems: (1) STARFM had a good effect in predicting the gradient information, but it cannot predict the instantaneous disturbance events in the short term. (2) STARFM did not consider reflectance directionality. (3) STARFM assumed that MODIS pixel is pure and homogeneous. In response to these problems, scholars have made improvements; the spatial-temporal adaptive algorithm for mapping reflectance change (STAARCH) and the enhanced STARFM method (ESTARFM) were two other examples of trials to improve the original STARFM to detect the land-cover change and make it applicable in the heterogeneous landscape $[18,19]$.

Emelyanova et al. conducted a comprehensive study to investigate the performance of STARFM and ESTARFM in two landscapes with contrasting spatial and temporal dynamics, and their results demonstrate that the performance of the data fusion methods is strongly associated with the spatial and temporal variance of the land cover [20]. Even though ESTARFM is better than STARFM in heterogeneous landscapes, it does not perform as well when predicting abrupt changes in land cover types. Additionally, the simulation accuracy is low when there is a large cloud cover. However, the difficulty in input data preparation (e.g., certain pairs of fine and coarse resolution images acquired on the same date) significantly limited their applicability. In order to accurately predict high-precision Landsat images and overcome the prediction error caused by large heterogeneous mutation regions, Zhu et al. proposed the flexible spatiotemporal data fusion model (FSDAF) and showed that FSDAF created more accurate fused images and retained more spatial detail than STARFM [21]. More importantly, FSDAF closely captures reflectance changes caused by land cover conversions, which is a major issue with the current spatiotemporal data fusion methods. In addition, FSDAF only requires a reference image for Landsat and MODIS and a MODIS image for the predicted time. FSDAF effectively reduces the amount of data input and is easily operated. 
At present, global land cover and land surface phenology products (MOD09GA) are available at $500 \mathrm{~m}$ spatial resolution from MODIS [22,23], but the $500 \mathrm{~m}$ spatial resolution is too coarse for most crop fields. This resolution often results in mixed pixels of different vegetation or crop types, which may have very different phenological growth cycles [24,25]. The time-series MOD13Q1 $250 \mathrm{~m}$ MODIS NDVI data are the primary source for most crop yield estimation models [26,27]. This study evaluated Landsat images of different dates to determine the optimal reference date for input fine image and then generated fused images of both MOD09GA and of MOD13Q1 and compared the results. In addition, we analyzed the effect of mixed pixels by comparing the accuracy of yield estimation of fusion products from the two different MODIS resolutions.

Here, we extend the application of fusion images to field-scale study. The main objective of this study was to evaluate the ability of a Landsat-MODIS data fusion methodology to generate field scale data at $30 \mathrm{~m}$ resolution. Since crop yield can be predicted accurately using NDVI (and other indices) obtained at the peak of the growing season (peak greenness) [28-30], MOD13Q1 is a 16-day product, for which we can identify the specific DOY 230 because the day with the highest NDVI value is within the 16-day period for the MOD13Q1 product. In this way, we evaluated the fusion outputs by first comparing them to Landsat NDVI at DOY 230, and then, for the best outputs, by assessing their ability to predict yield. Specifically, our aims were to: (1) evaluate the fusion results of Landsat-MODIS data (MOD09GA and MOD13Q1); (2) evaluate the effects of different Landsat image dates on the results of the time-series fusion NDVI; and (3) assess the fusion results of Landsat-MODIS data (MOD09GA or MOD13Q1) over three cotton plots through MDI and review the impact on the accuracy of fused Landsat-MODIS images.

\section{Materials and Methods}

\subsection{Study Area}

The study area is located on the western side of the southern San Joaquin Valley of California, USA, and has been extensively used for RS time-series research [31,32]. Cloud-free Landsat-MODIS pairs were available throughout the year because the San Joaquin Valley has a Mediterranean climate, with hot and dry summers (maximum of $40{ }^{\circ} \mathrm{C}$ and a day/night difference of approximately $16^{\circ} \mathrm{C}$ ) and cool and wet winters (average annual rainfall of $854 \mathrm{~mm}$ ). The rainy season normally runs from November to April, and there was little rainfall recorded during the study period of May-September 2002 (https: / / www.usclimatedata.com/climate/california/united-states (accessed on 29 July 2021)). Three cotton plots (labeled A, B, and) were selected as the study area (Figure 1) because detailed cotton yield data for these fields were available for validation. Compared to MODIS images, Landsat NDVI has a relatively fine spatial resolution of $30 \mathrm{~m}$ (Figure 1b), and the mixed pixel problem is therefore not serious. Figure $1 \mathrm{~b}-\mathrm{d}$ present the Landsat and MODIS images of the three plots, each of which covers an area of approximately 9 pixels at the $250 \mathrm{~m}$ resolution of MOD13Q1 (Figure 1c) and only 1 pixel at the $500 \mathrm{~m}$ resolution of MOD09GA (Figure 1d). Figure 2 shows the yield map of the study plots.

\subsection{Satellite Images}

We have adopted an identifying nomenclature as follows: $\mathrm{NDVI}_{\mathrm{L} 30 \_174}$ identifies Landsat NDVI at $30 \mathrm{~m}$ resolution on DOY $174, \mathrm{NDVI}_{\mathrm{M} 250}$ identifies NDVI from MODIS $250 \mathrm{~m}$ imagery, NDVI ${ }_{\mathrm{F} 250 \_174}$ identifies NDVI on DOY 174 from MODIS $250 \mathrm{~m}$ imagery fused with a Landsat image, and NDVI ${ }_{\mathrm{F} 500 \_174}$ identifies NDVI on DOY 174 from MODIS $500 \mathrm{~m}$ imagery fused with a Landsat image. Other products use the same format. 
a

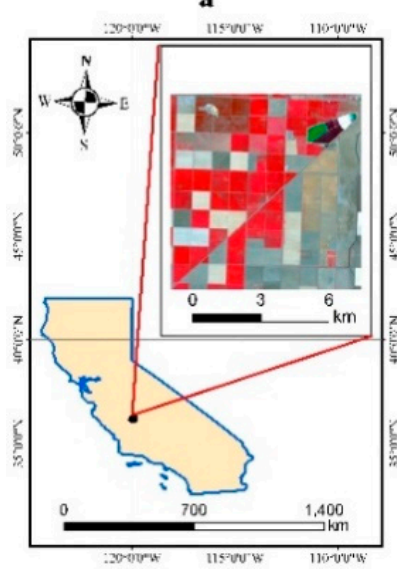

b

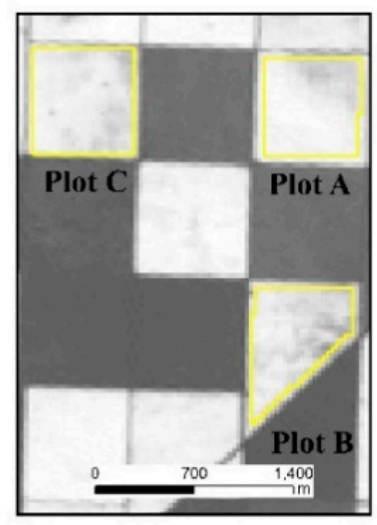

c

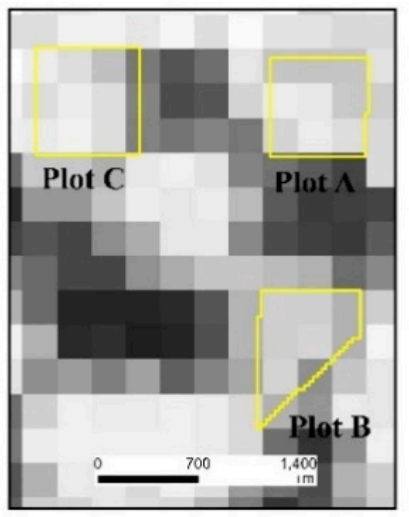

d

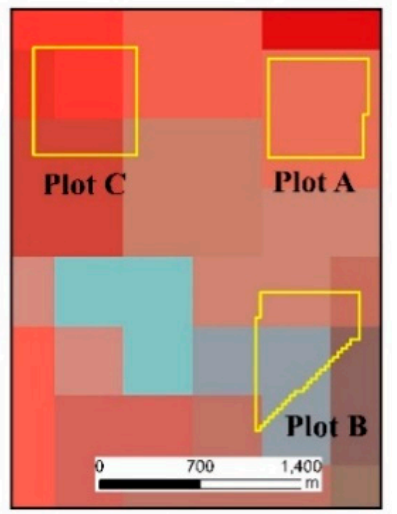

Figure 1. Map of the study area; (a) California map and Landsat $30 \mathrm{~m}$ image of the study area on DOY 206; (b) study plots overlain on Landsat NDVI on DOY 206; (c) study plots overlain on MOD13Q1 250 m (MODIS NDVI) image on DOY 193; (d) study plots overlain on MOD09GA $500 \mathrm{~m}$ image (Band 2, band 1, band 4) on DOY 206.

a

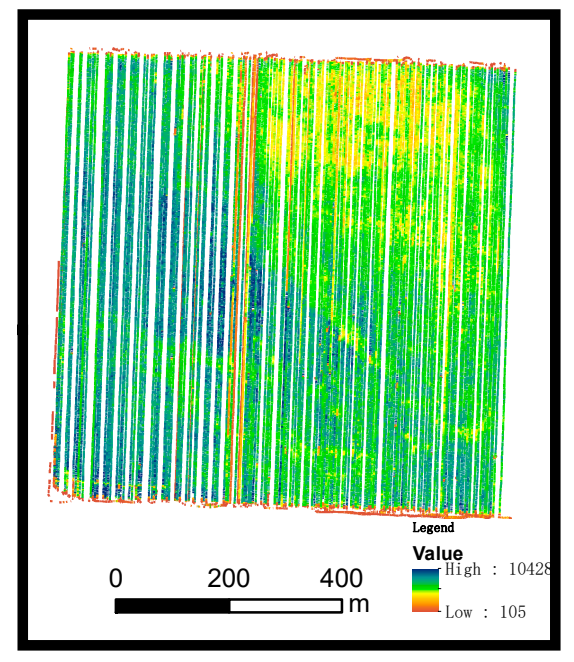

b

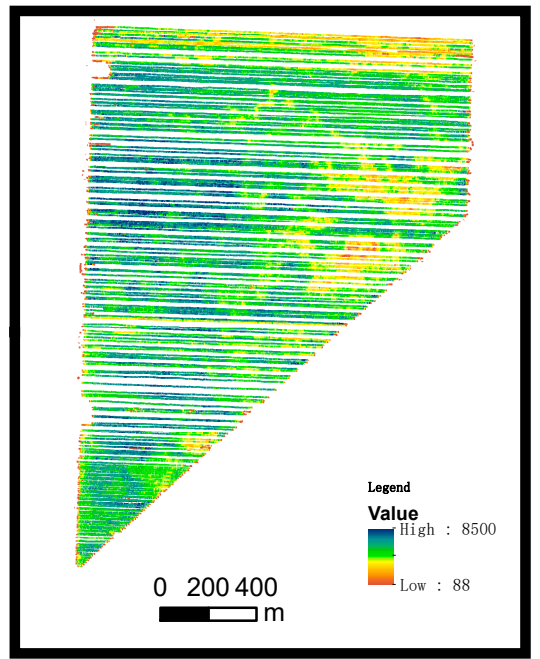

C

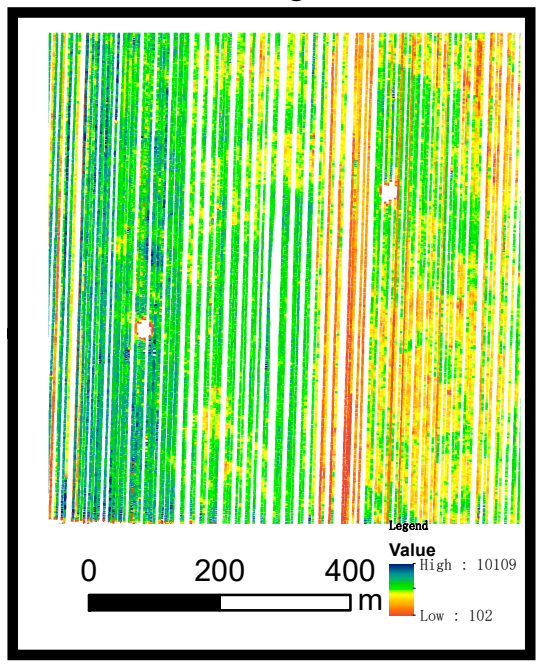

Figure 2. Cotton yield map (2002) of the study plots (a) plot A; (b) plot B; (c) plot C.

Landsat images (TM 5 and ETM 7) of the study area covering the cotton growth period from sowing in May to October were obtained for 2002 (http: / / earthexplorer.usgs.gov (accessed on 29 July 2021)). The temporal resolution of Landsat images was 8 days, and the spatial resolution was $30 \mathrm{~m}$. Radiometric calibration and atmospheric correction were conducted during the preprocessing of the Landsat images. The Landsat NDVI (NDVI $\left.\mathrm{L}_{\mathrm{L} 0}\right)$ time-series covering the May-September period (defoliant spraying in September) was calculated using the 'Band math' function of ENVI 5.1 (Esri, Redlands, CA, USA).

MOD13Q1 and MOD09GA products from 2002 were obtained from the NASA Reverb website (http:/ / reverb.echo.nasa.gov (accessed on 29 July 2021)). The MOD13Q1 product includes $250 \mathrm{~m}$ NDVI data $\left(\mathrm{NDVI}_{\mathrm{M} 250}\right)$ and quality assessment (QA) information, while the MOD09GA NDVI data $\left(\mathrm{NDVI}_{\mathrm{M} 500}\right)$ was calculated from atmospherically corrected surface reflectance values. The MODIS Reprojection Tool (MRT; https:/ / lpdaac.usgs.gov (accessed on 29 July 2021)) was used to convert HDF format images into ENVI standard format. In this study, to fit the requirements of the FSDAF data fusion model, MOD13Q1 and MOD09GA data were resampled to $240 \mathrm{~m}$ and $480 \mathrm{~m}$ in order to make better geo-spatial correction and integration with Landsat $30 \mathrm{~m}$ in integral proportion. Table 1 had show the dates and number of Landsat and MODIS images used in the study. 
Table 1. Dates and number of Landsat and MODIS images used in the study over the cotton growing season from May to October in 2002.

\begin{tabular}{|c|c|c|c|}
\hline Product & Sensors & Date & Number of Images \\
\hline Landsat & TM 5 & $\begin{array}{l}6 \text { May; } 22 \text { May; } 7 \text { June; } 23 \text { June; } 1 \text { July; } \\
17 \text { July; } 2 \text { August; } 26 \text { August; } \\
11 \text { September; } 27 \text { September; } \\
13 \text { October; } 29 \text { October; }\end{array}$ & 12 \\
\hline \multirow{3}{*}{ MODIS } & ETM 7 & $\begin{array}{l}14 \text { May; } 30 \text { May; } 15 \text { June; } 9 \text { July; } 25 \text { July; } \\
18 \text { August; } 3 \text { September; } 19 \text { September; } \\
5 \text { October; } 21 \text { October; }\end{array}$ & 10 \\
\hline & MOD13Q1 & $\begin{array}{l}25 \text { May; } 10 \text { June; } 26 \text { June; } 12 \text { July; } \\
28 \text { July; } 13 \text { August; } 29 \text { August; } \\
14 \text { September; }\end{array}$ & 8 \\
\hline & MOD09GA & $\begin{array}{l}7 \text { June; } 23 \text { June; } 17 \text { July; } 25 \text { July; } \\
2 \text { August; } 18 \text { August; } 26 \text { August; } \\
3 \text { September; } 11 \text { September; }\end{array}$ & 9 \\
\hline
\end{tabular}

Note that MODIS and Landsat bands use different band number sequences in the FSDAF model. It can relate them using the following Landsat product bands 1, 2, 3, 4, 5, 7 vs. MOD09GA product bands 3, 4, 1, 2, 6, 7 .

\subsection{Yield Data}

Yield data were collected using a cotton yield monitor onboard the harvester (ModelAG700, AGRIplan, Stow, MA, USA; www.agriplaninc.com (accessed on 29 July 2021)), and the yield accuracy (validated with manually harvested field plots) was estimated to be between 95 and $98 \%$ for the pixels of approximately $4.5 \mathrm{~m}$ by $4.5 \mathrm{~m}$ [33]. The cotton yield monitor uses an optical sensor to detect the volume of cotton as it passes through the machine. The crop volume is recorded on a storage device with location data from an onboard GPS, and a shape-file yield map is later produced using proprietary software.

The yield map was produced in 3 steps [34]:

Step 1: ASCII text and database files were converted into vector shape files using ArcGIS;

Step 2: The shape files were converted to raster, with the output raster cell size set to $0.5 \mathrm{~m} \times 0.5 \mathrm{~m}$ to generate the yield map;

Step 3: The outlying yield values caused by grain time lag and yield surges were removed using a statistical identifier based on a moving average mean and standard deviation. If the yield was less than or greater than three standard deviations from the average, it was identified as an outlier and removed.

\subsection{FSDAF Model}

The FSDAF model synthesizes frequent high spatial resolution images by blending frequent coarse spatial resolution data, such as those from MODIS, with less frequent high spatial resolution data, such as those from Landsat [21]. FSDAF requires only Landsat and MODIS images at the reference time and MODIS images at each of the predicted times, and therefore effectively minimizes the number of input images. By using a single reference image and implementing the model for each additional MODIS image over the growing season, a time-series of high-resolution NDVI images is generated. As FSDAF uses simple principles and requires only one fine-resolution image as an input, it has the potential to increase the availability of high-resolution time-series data in support of studies of rapid land surface dynamics.

Implementation of the FSDAF model required six steps:

(1) manual delineation of the study area on the Landsat image at $t$;

(2) calculation of the change in MODIS NDVI between $\mathrm{t} 1$ and $\mathrm{t} 2$;

(3) prediction of the Landsat NDVI image at t2 using fine-resolution temporal change in MODIS NDVI and calculation of residuals at each MODIS pixel; 
(4) prediction of the Landsat NDVI image from the MODIS NDVI image at $\mathrm{t} 2$ with a Thin Plate Spline (TPS) interpolator [35], which is a spatial interpolation technique for point data based on spatial dependence;

(5) distribution of the residuals based on TPS prediction;

(6) obtaining the final prediction of NDVI at each Landsat pixel using information in the neighborhood.

In this study, we compared the accuracy of the FSDAF fusion results using different MODIS products (MOD09GA and MOD13Q1) and Landsat images of different reference dates. Examples of DOY 206 imagery available for fusion are shown in Figure 3.
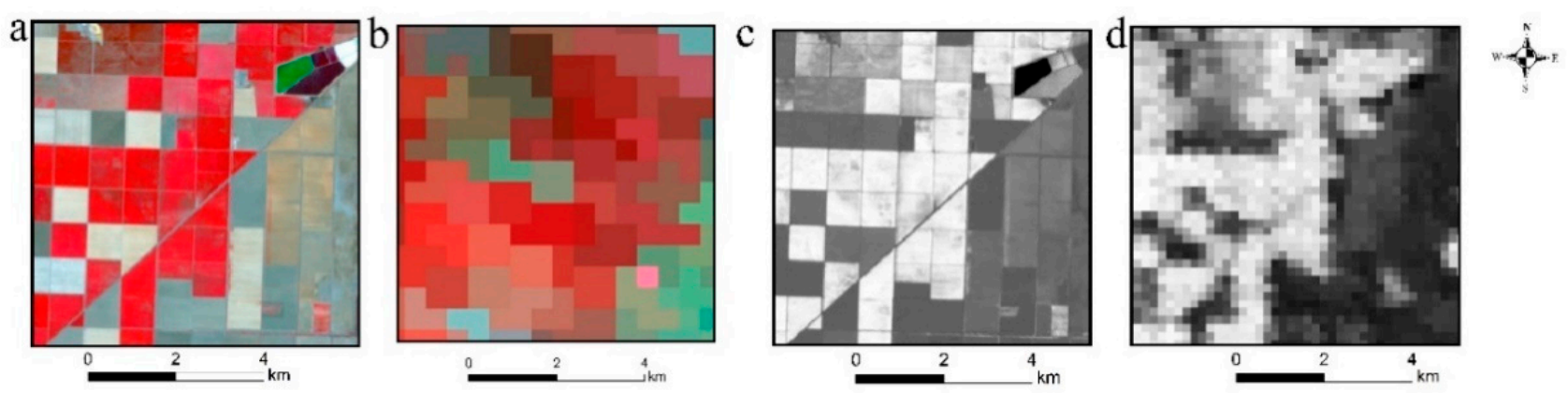

Figure 3. FSDAF input images (a) Landsat $30 \mathrm{~m}$ image on DOY 206; (b) MOD09GA 500 m image on DOY 206; (c) Landsat 30 m NDVI on DOY 206; (d) MODIS 250 m NDVI on DOY 193).

\subsection{Selection of Images for the Fusion Model}

Figure 4 shows the time-series $\mathrm{NDVI}_{\mathrm{L} 30}$ curve of cotton growth in the study area and the $\mathrm{NDVI}_{\mathrm{L} 30}$ derivatives obtained from the Landsat images from May to October in 2002 extracted from OriginPro 8.5 (https: / / www.originlab.com (accessed on 29 July 2021)). From the trend of NDVI derivatives, it is apparent that the cotton began to grow quickly on DOY 174, grew at a steady rate until DOY 206, and then fell gradually until DOY 254. We identified three stages, Early, Middle, and End, and selected DOY 230 as the peak of the growing season. A single Landsat image from each stage (DOY 174, 206, and 254, respectively) was selected as the reference date for FSDAF in order to compare the effect of the different dates on the accuracy of the fusion model in duplicating Landsat NDVI on DOY 230.

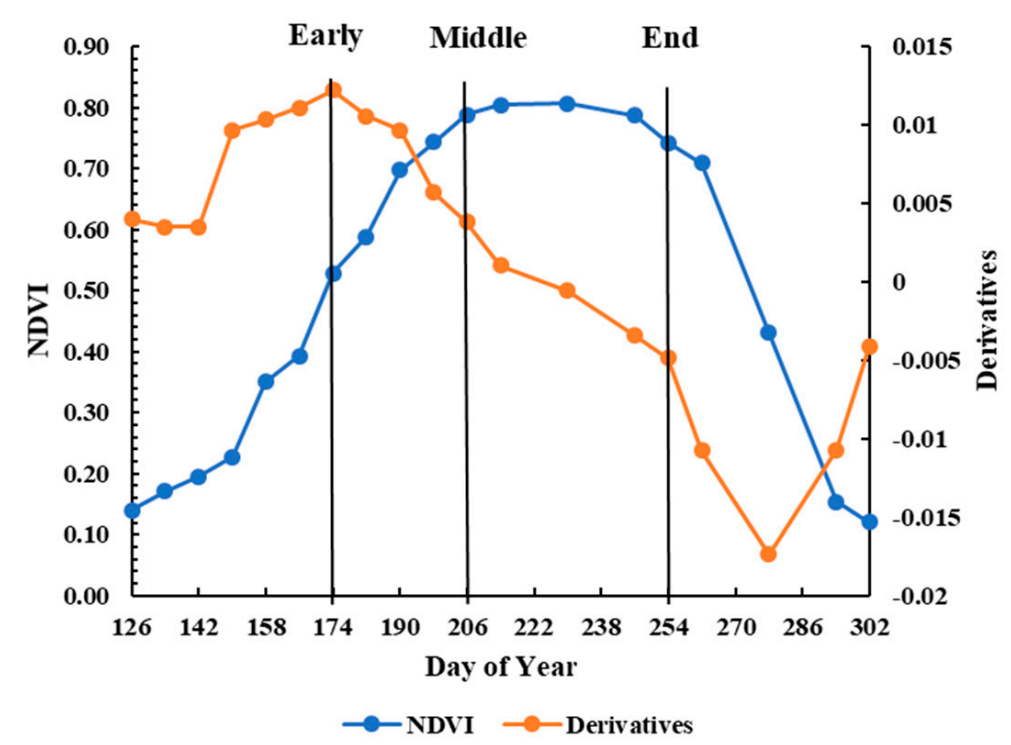

Figure 4. Time-series Landsat NDVI and derivatives curves over the cotton growing season. 


\subsection{Mixed Degree Index (MDI)}

The MODIS products input into FSDAF model in this paper were MOD09GA and MOD13Q1, and the fusion process must account for the differences in vegetation change in the MODIS images. For example, the three different plots occupy different numbers of pixels; taking MOD09GA products as an example (Figure 5), plot A has four pixels, plot B has five pixels, and plot $C$ has six pixels. From Figure 1, due to the serious mixed problem in the MODIS product, the surrounding area around the three plots is so different that it is important to consider the effects of crop structure and surrounding land cover on the fusion results (Figure 6). However, the pixels occupied by the plots are not all pure pixels; thus, it is necessary to analyze the mixing degree of the pixels occupied by the plots. In this paper, we first propose the MDI to evaluate the degree of pixel mixing and the fusion results of different plots; its calculation principles are described by Equations (1)-(3). It was constructed to evaluate the accuracy and time-series fusion results of the different cotton plots, after which the different yield estimation models were compared.
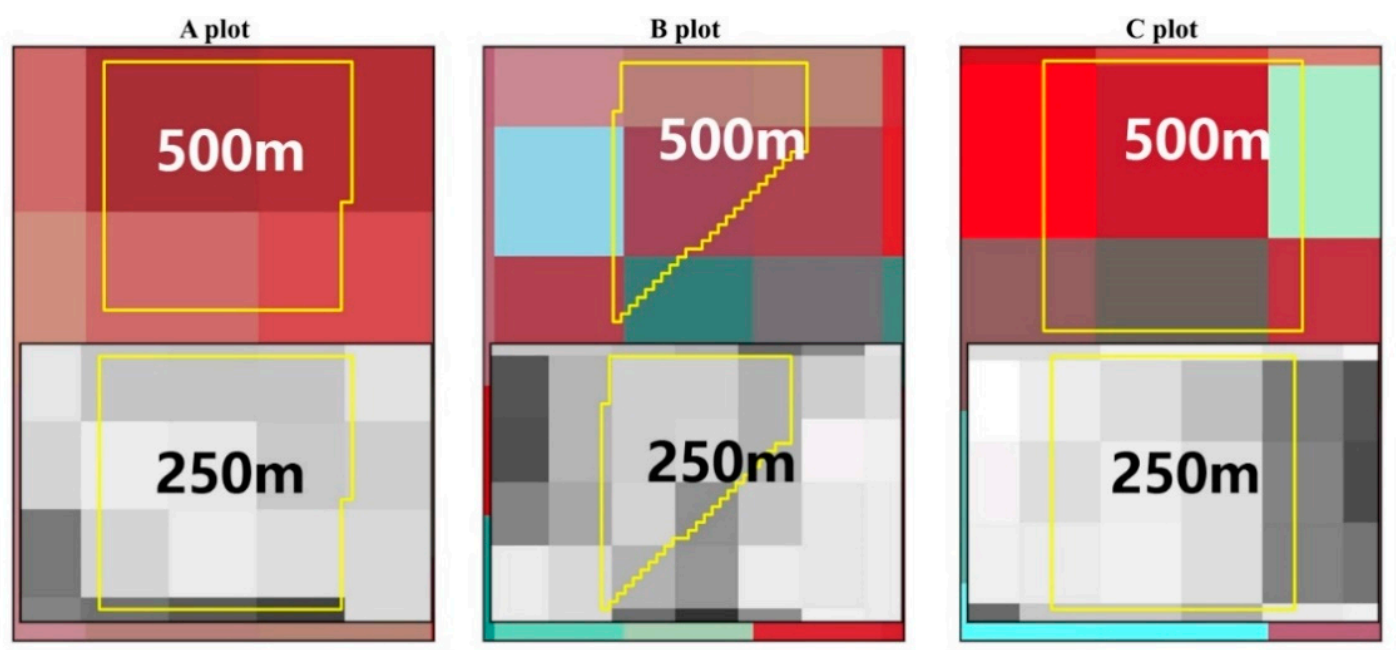

Figure 5. Three plots shown in MOD09GA (500 m) and MOD13Q1 (250 m).

(1) Mixed pixel area ratio $\left(\mathrm{M}_{\mathrm{PAR}}\right)$

$$
\mathrm{M}_{\mathrm{PAR}}=\frac{S_{P}}{S_{W}} * \frac{S_{P}}{S_{Y}}
$$

Note: $S_{P}$ is the area of the pixel of the plot; $S_{w}$ is the area of a pure pixel $(250 \mathrm{~m} \times 250 \mathrm{~m}$ or $500 \mathrm{~m} \times 500 \mathrm{~m}) ; S_{Y}$ is the area of the plot.

(2) NDVI proportion (NDVI Pro

Different proportions of NDVI values of surrounding ground features are different in the two MODIS products ( $250 \mathrm{~m}$ or $500 \mathrm{~m}$ ); this paper uses the $\mathrm{NDVI}_{\text {Pro }}$ to consider the pixel NDVI influenced by MODIS products of different resolutions.

$$
\mathrm{NDVI}_{\text {Pro }}=\frac{A B S\left(\mathrm{NDVI}_{\mathrm{M}}-\mathrm{NDVI}_{\mathrm{L}}\right)}{M A X\left(\mathrm{NDVI}_{\mathrm{L}}, \mathrm{NDVI}_{\mathrm{M}}\right)}
$$

Note: NDVIM is the NDVI of the MODIS product $(250 \mathrm{~m}$ or $500 \mathrm{~m}) ; \mathrm{NDVI}_{\mathrm{L}}$ is the NDVI of Landsat (30 m).

(3) Mixed degree index (MDI)

$$
\mathrm{MDI}=\sum_{i=1}^{n} \mathrm{M}_{\mathrm{PAR}} * \mathrm{NDVI}_{\mathrm{Pro}}
$$

Note: (a) Number the pixels one by one, from left to right, top to bottom, $(1,2,3 \ldots n)$; (b) Pixels for which the degree is less than $1 \%$ are not included; (c) The lower right side 
of plot B is largely affected by fallow farmland, and it is divided into different farms by a road, which covers $13 \%$ of the total area (Figures 5 and 6); (d) MDI values from 0 to 1.

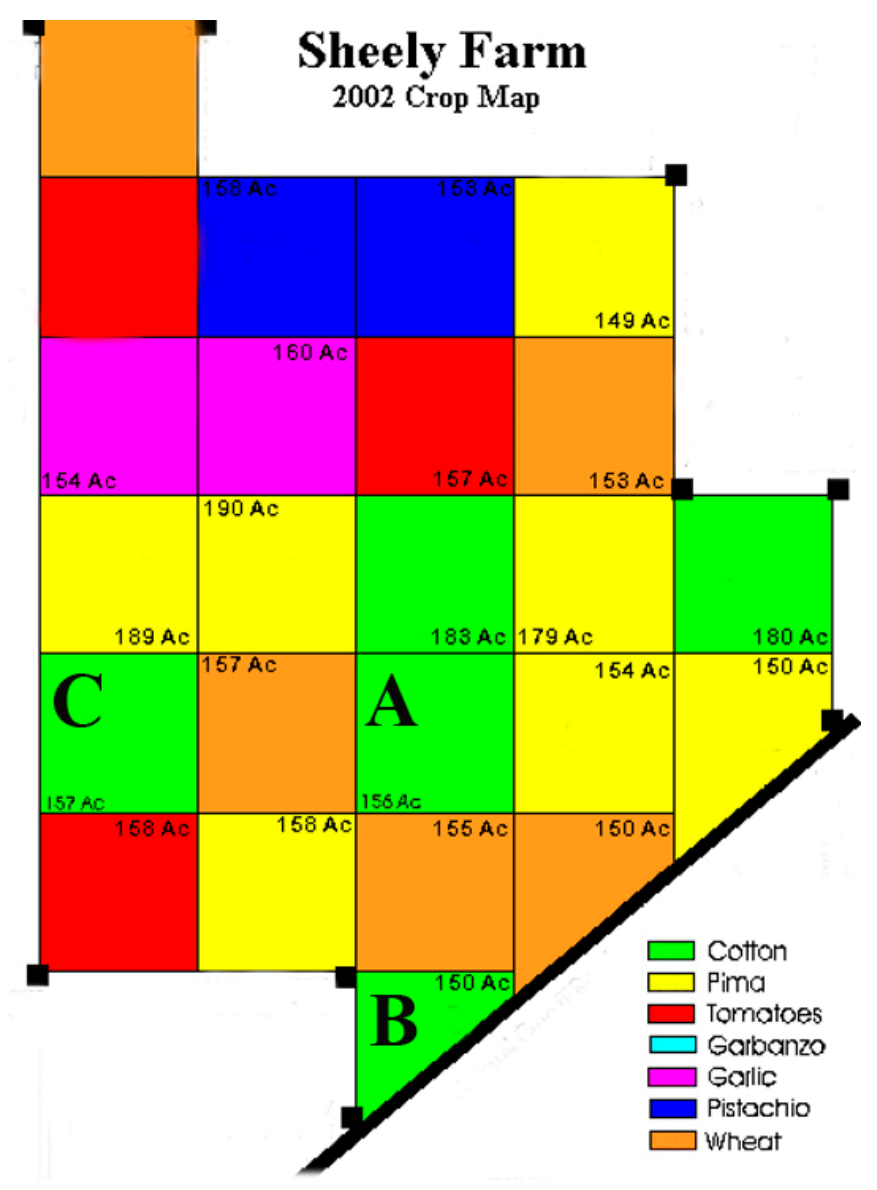

Figure 6. Three plots shown on the Sheely Farm crop map.

\subsection{Yield Estimation Model}

Correlation regression analysis was used to analyze the correlation between the yield and the $\mathrm{NDVI}_{\mathrm{L}}$ or the predicted NDVI from the fusion results $\left(\mathrm{NDVI}_{\mathrm{F}}\right)$. The regression model was established with SPSS19.0 (http:/ / www.ibm.com (accessed on 29 July 2021)). Therefore, this paper took the $\mathrm{NDVI}_{\mathrm{L}}$ and the $\mathrm{NDVI}_{\mathrm{F}}$ as the input variables (both $\mathrm{NDVI}_{\mathrm{F} 500}$

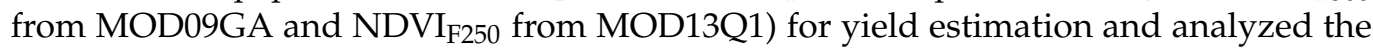
accuracy to validate the feasibility of fusion images for yield estimations.

$$
\text { Yield } \operatorname{Model}(y)=a * x+b
$$

where $y$ is the predicted yield, $x$ is NDVI, predicted NDVI from fusion result, respectively; $a$ and $b$ are coefficients.

\subsection{Accuracy Evaluation Method}

(1) Evaluation of FSDAF

The model was evaluated using the adjusted decision coefficient $\left(R^{2} \mathrm{Adj}\right.$, Equation (5). From the scatter between the $\mathrm{NDVI}_{\mathrm{F}}$ and the $\mathrm{NDVI}_{\mathrm{L}}$, the $R^{2}$ Adj was calculated, and the fusion results were evaluated from $R^{2}$ Adj.

$$
R_{\text {Adj }}^{2}=\frac{\sum_{i=1}^{n}\left(x_{i}-\bar{x}\right)^{2}}{\sum_{i=1}^{n}(x-\bar{x})^{2}}
$$


where $x$ is the $\mathrm{NDVI}_{\mathrm{F}}, x_{i}$ is the $\mathrm{NDVI}_{\mathrm{L}}$, and $\bar{x}$ is the average $\mathrm{NDVI}_{\mathrm{L}}$.

The closer to 1 the $R^{2}$ Adj, the better the FSDAF fusion result.

(2) Evaluation method for the yield estimation model

The general yield model equation is shown as Equation (4). The yield models were evaluated using the decision coefficient $\left(R^{2}\right)$ and the root mean square error (RMSE) [36,37].

\subsection{Flow Chart of Data Analysis, Model Validation, and Evaluation}

In this paper, MOD09GA and MOD13Q1 products and Landsat images were input into the FSDAF fusion model, and NDVI $\mathrm{F}_{2} 250$ and NDVI NDVI $\mathrm{F}_{\mathrm{F} 500}$ were obtained. In addition, MDI was constructed to evaluate the mixing degree of different plots in the different MODIS products. Finally, the cotton yield estimation models were established, and the accuracy evaluation was carried out. A flow chart is shown in Figure 7.

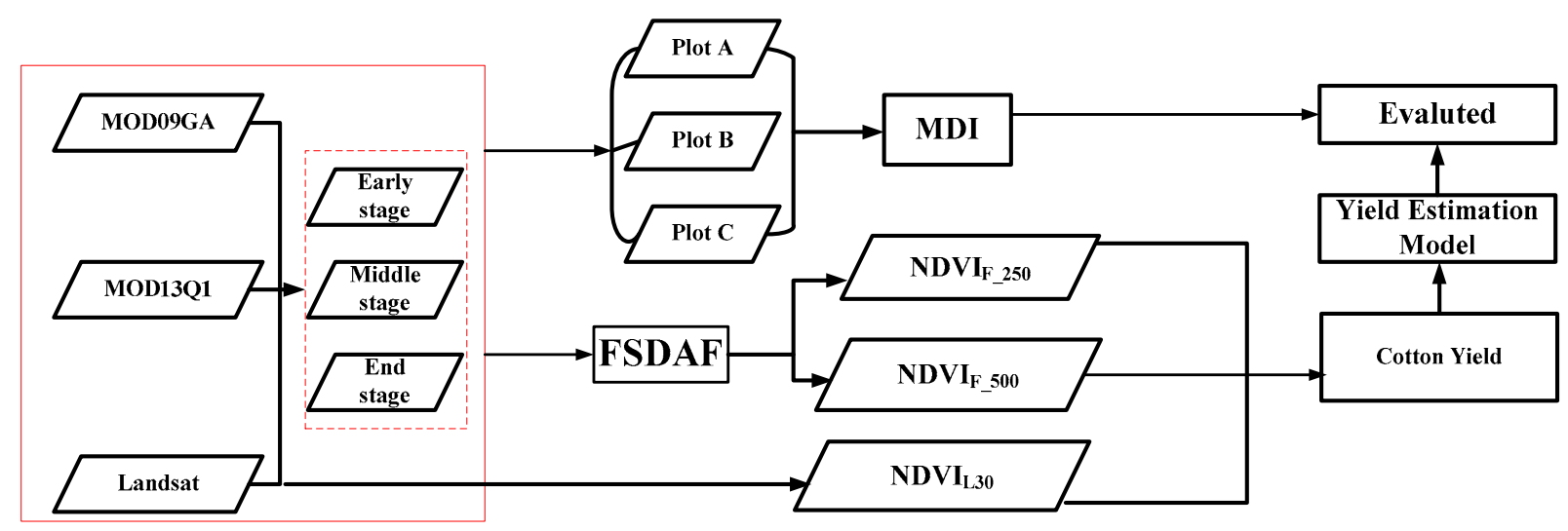

Figure 7. Flow chart of the technique employed in this study.

\section{Results}

\subsection{Time-Series NDVI of the MODIS and Landsat Images}

Figure 8 shows linear interpolations of NDVI across the time-series of each of the input images for all three plots. Landsat $\left(\mathrm{NDVI}_{\mathrm{L} 30}\right)$ and MODIS images (especially $\mathrm{NDVI}_{\mathrm{M} 250}$ ) show a similar time trend, even though the spatial resolution of the two MODIS products is much greater, at $250 \mathrm{~m}$ and $500 \mathrm{~m}$, than the $30 \mathrm{~m}$ of the Landsat images. The problems caused by mixed pixels, as outlined by Fitzgerald et al., may be masked by the fact that the mix of vegetation within the large pixels in this agricultural setting relates to different crops that are all at relatively the same growth stage [38]. The time-series $\mathrm{NDVI}_{\mathrm{L} 30}$ and $\mathrm{NDVI}_{\mathrm{M} 250}$ show some difference in the early portion of the cotton growth season (Figure 8a), which align almost perfectly by the middle of the season and then diverge again in the latter portion. The $\mathrm{NDVI}_{\mathrm{M} 500}$ series has a similar trajectory to $\mathrm{NDVI}_{\mathrm{L} 30}$, but the values are somewhat lower than those of $\mathrm{NDVI}_{\mathrm{L} 30}$ and $\mathrm{NDVI}_{\mathrm{M} 250}$, especially in the middle portion of the cotton growing season, where there is an unexplained dip in reflectance.

Figure $8 \mathrm{~b}$ shows the time-series $\mathrm{NDVI}_{\mathrm{L} 30}$ of the three cotton plots of the study area. The three plots have similar growth curves, with plot A exhibiting slightly better growth than plots $C$ and B. From this similarity in growth pattern, it can be assumed that any plot difference in yield estimation accuracy by $\mathrm{NDVI}_{\mathrm{F} 250}$ and $\mathrm{NDVI}_{\mathrm{F} 500}$ is due to the difference in pixel mixing rather than crop condition. 

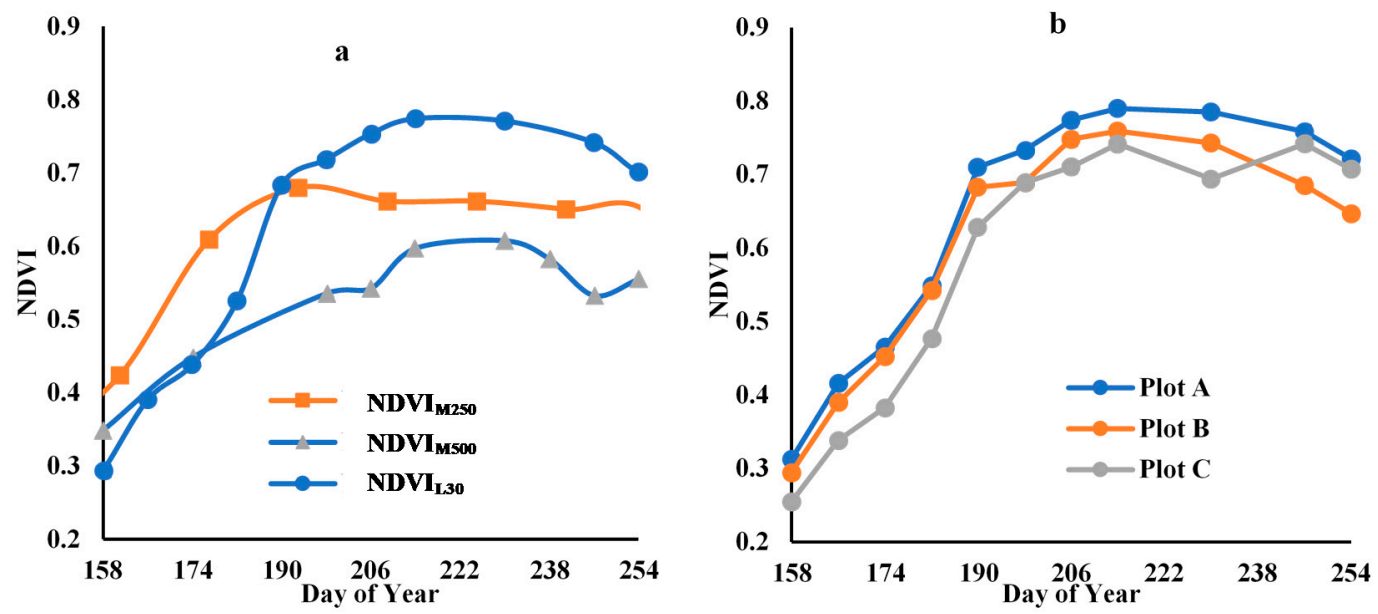

Figure 8. Time-series NDVI curve (a) $\mathrm{NDVI}_{\mathrm{M} 500}, \mathrm{NDVI}_{\mathrm{M} 250}$, and $\mathrm{NDVI}_{\mathrm{L} 30}$; (b) $\mathrm{NDVI}_{\mathrm{L} 30}$ of the three cotton plots).

\section{2. $M D I$ of $A / B / C$ at Different Spatial Resolutions}

Figure 9 shows the MDI of the three plots at $250 \mathrm{~m}$ and $500 \mathrm{~m}$ spatial resolution. It can be seen from Figure 9 that the MDI in the $500 \mathrm{~m}$ MODIS product of plot $\mathrm{A}$ is better than that of $B$ but slightly lower than that of $C$. Figure 5 shows that the proportion of pure pixels at $250 \mathrm{~m}$ occupied by plot $C$ was greater than that of $A$. For plot $B$, the MDI in $250 \mathrm{~m}$ product was higher than that in $\mathrm{A}$ and $\mathrm{C}$. With respect to the location of plot $\mathrm{B}$, the MDI was increased due to the influence of the plot shape and surrounding crop types (Figure 6). B was largely affected by fallow farmland, and it was divided into different sections by a road, which covered $13 \%$ of the total area.

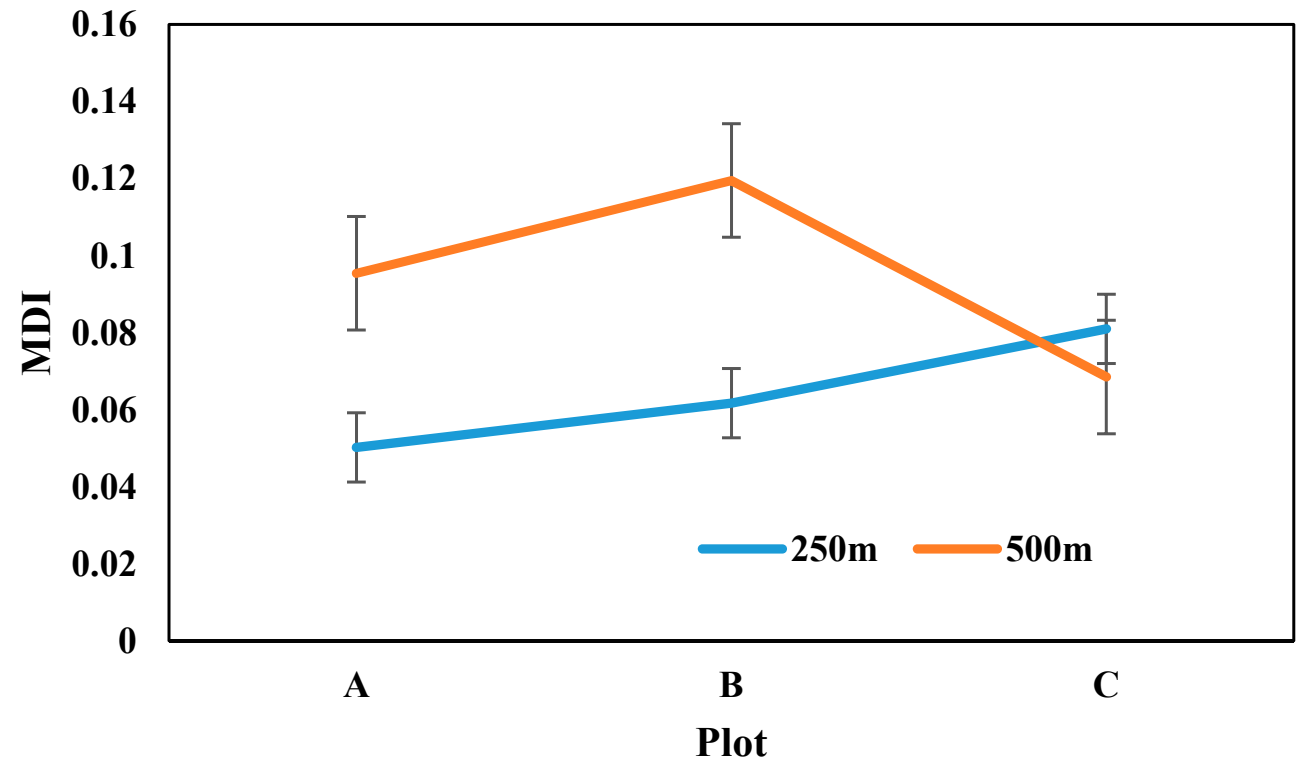

Figure 9. MDI curves of the three plots at the scales of $250 \mathrm{~m}$ and $500 \mathrm{~m}$.

\subsection{Landsat-MODIS Fusion Results}

3.3.1. Results of the Fusion of Landsat at Different Reference Dates with $500 \mathrm{~m}$ MOD09GA

Three single-date Landsat NDVI images (DOY 174, DOY 206, DOY 254) were used in FSDAF to explore the influence of different reference dates on the accuracy of predicting the peak of the growing season through Landsat/MODIS fusion $\left(\mathrm{NDVI}_{\mathrm{F} 500}\right)$. As an example of the results, Figure 10 provides a visual comparison of fusion results at peak season (DOY 230) using Landsat images on DOY 174, DOY 206, and DOY 254 as reference images. 
The overall view of the fusion results is similar to the Landsat image, even capturing differences in crop conditions, observable as lighter and darker areas within the images.

a

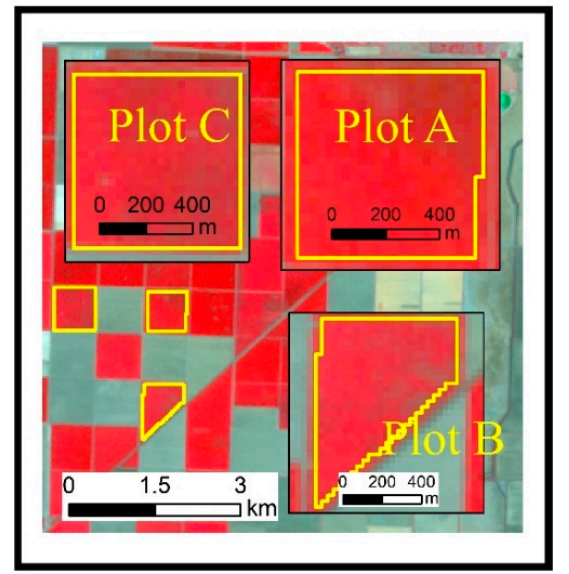

c

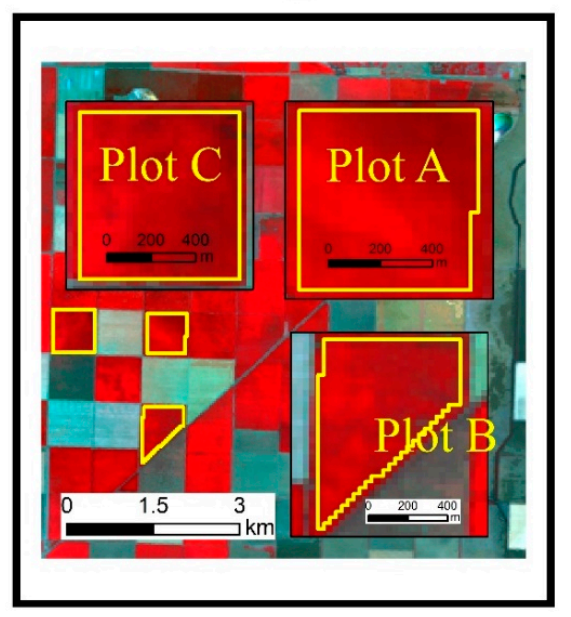

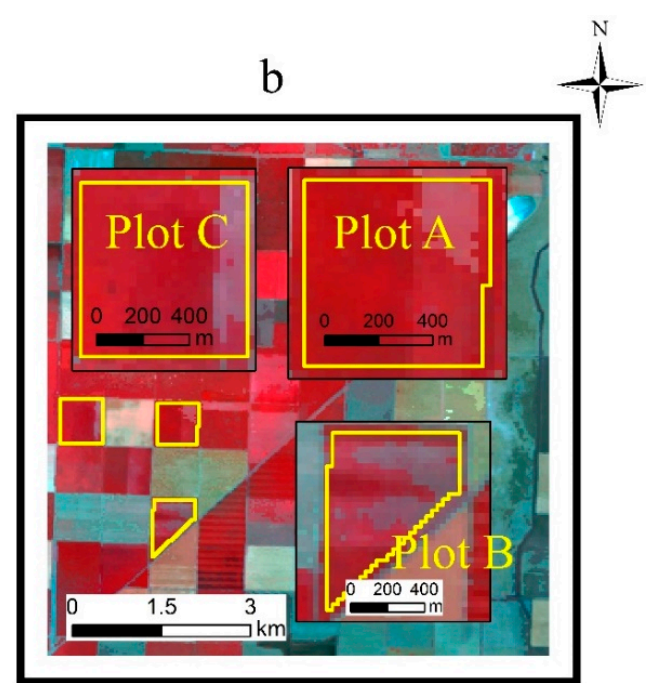

d

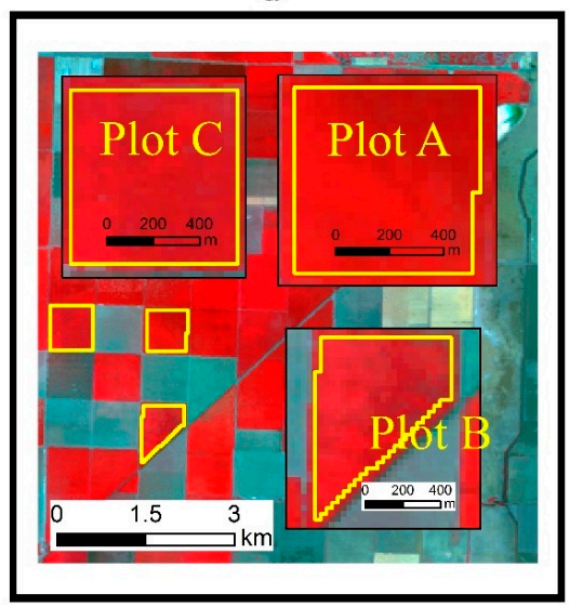

Figure 10. A visual comparison of fusion results; (a) Landsat image on DOY 230; (b-d) DOY 230 image from the fusion of reference Landsat images of DOY 174, DOY 206, and DOY 254 with MODIS $500 \mathrm{~m}$ imagery.

The NDVI values of the fused $500 \mathrm{~m}$ MODIS (NDVI $\mathrm{F}_{\mathrm{F} 50 \_230}$ ) with three different reference Landsat images over all three plots were compared to Landsat NDVI at peak greenness (NDVI $\mathrm{L}_{\mathrm{L} 30230}$ ) using scatterplots and $R^{2}$ values. Table 2 provides the results of linear regression using reference images from the early, middle, and end stages of the growing season. A comparison of $R^{2}$ values shown in Figure 11 and Table 2 indicates that $\mathrm{NDVI}_{\mathrm{F500} \_230}$, which uses $\mathrm{NDVI}_{\mathrm{L} 30 \_206}$ as a reference image, has a higher correlation with Landsat at DOY 230 than fused images using $\mathrm{NDVI}_{\mathrm{L} 30 \_174}$ or $\mathrm{NDVI}_{\mathrm{L} 30 \_254}$ as reference images. These results indicate that using a reference image from the middle stage of the crop growth season provides a fusion product that better represents peak growth than using reference images from early or late in the growing season. 
Table 2. Results of linear regression between the fusion product $\mathrm{NDVI}_{\mathrm{F} 500 \_230}$ using different reference dates and NDVI $\mathrm{L} 30 \_230_{2}$ in 3 plots.

\begin{tabular}{|c|c|c|c|}
\hline Plot & $\begin{array}{c}\text { Early Stage } \\
\left(\mathrm{NDVI}_{\mathrm{L} 30 \_174}\right)\end{array}$ & $\begin{array}{l}\text { Middle Stage } \\
\left(\text { NDVII }_{\text {L30_206 }}\right)\end{array}$ & $\begin{array}{c}\text { End Stage } \\
\left(\mathrm{NDVI}_{\mathrm{L} 30 \_254}\right)\end{array}$ \\
\hline A & $\begin{array}{c}y=0.3225 x+0.5601 \\
R^{2}=0.3298\end{array}$ & $\begin{array}{c}y=1.5028 x-0.5154 \\
R^{2}=0.6586\end{array}$ & $\begin{array}{c}y=0.8208 x+0.1313 \\
R^{2}=0.1401\end{array}$ \\
\hline B & $\begin{array}{c}y=0.2752 x+0.5978 \\
R^{2}=0.3775\end{array}$ & $\begin{array}{c}y=0.6046 x+0.2604 \\
R^{2}=0.652\end{array}$ & $\begin{array}{c}y=0.5426 x+0.3506 \\
R^{2}=0.2626\end{array}$ \\
\hline C & $\begin{array}{c}y=0.2282 x+0.5908 \\
R^{2}=0.3962\end{array}$ & $\begin{array}{c}y=0.8174 x+0.0569 \\
R^{2}=0.6599\end{array}$ & $\begin{aligned} y= & 1.092 x-0.0946 \\
& R^{2}=0.4449\end{aligned}$ \\
\hline $\mathrm{ABC}$ & $\begin{array}{c}y=0.2302 x+0.6105 \\
R^{2}=0.3539\end{array}$ & $\begin{array}{c}y=0.6931 x+0.1778 \\
R^{2}=0.5872\end{array}$ & $\begin{aligned} y= & 0.615 x+0.2873 \\
& R^{2}=0.3105\end{aligned}$ \\
\hline
\end{tabular}
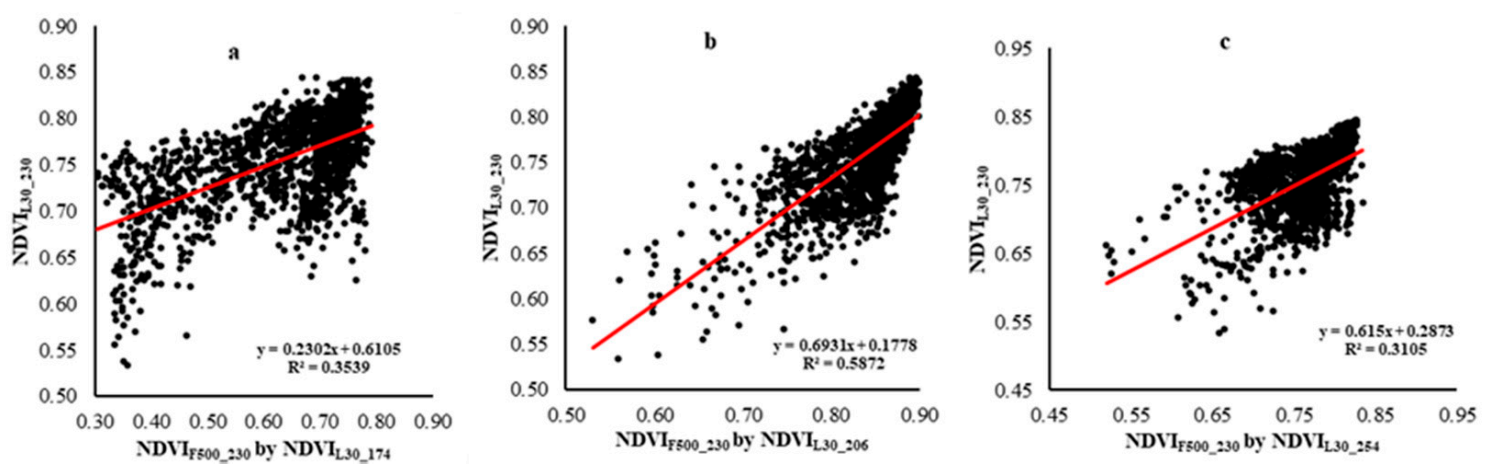

Figure 11. Scatterplots showing the relationship between the fusion products $\mathrm{NDVI}_{\mathrm{F} 500}$ and $\mathrm{NDVI}_{\mathrm{L} 30} ; \mathrm{NDVI}_{\mathrm{L} 30 \_230}$ versus $\mathrm{NDVI}_{\mathrm{F} 500 \_230}$ using (a) NDVI $\mathrm{L}_{20 \_174},(\mathbf{b}) \mathrm{NDVI}_{\mathrm{L} 30 \_206}$, and (c) NDVI $\mathrm{L}_{\text {30_254 }}$ for all pixels of 3 plots).

\subsubsection{Results of the Fusion of Landsat at Different Reference Dates with $250 \mathrm{~m}$ MOD13Q1}

Landsat images from the early, middle, and end stages of the cotton growth season were used in FSDAF with $\mathrm{NDVI}_{\mathrm{M} 250}$, as was completed with the $500 \mathrm{~m}$ MOD09GA product. Figure 12 presents a visual comparison of Landsat at peak growth (NDVI $\mathrm{L}_{\text {L3__230 }}$ ) with fused $250 \mathrm{~m}$ MODIS images (NDVI $\mathrm{F}_{250} 225$ ) using three different Landsat reference images (DOY 174, DOY 206, and DOY 254).

Figure 13 shows scatterplots of $\mathrm{NDVI}_{\mathrm{L} 30 \_230}$ versus $\mathrm{NDVI}_{\mathrm{F} 250 \_225}$ using different reference dates. These scatterplots show slightly higher correlation values than those of MOD09GA, but the trend is the same, with NDVI $\mathrm{F}_{250 \_225}$ using $\mathrm{NDVI}_{\mathrm{L} 30 \_206}$ as reference being slightly better than those using $\mathrm{NDVI}_{\mathrm{L} 30 \_174}$ or $\mathrm{NDVI}_{\mathrm{L} 30 \_254}$. Table 3 presents results for each plot separately and shows an anomaly for plot $\mathrm{B}$, in which the results using both early and late-season reference images provide higher $R^{2}$ values than the mid-season reference image. This may be due to the unexplained flattening of the growth curve around DOY 200 in plot $B$ as revealed in Figure 8 b, or it may be due to the irregular shape of plot $B$ compared to the square outlines of plots $A$ and $C$. This irregular shape may exacerbate the influence of mixed pixels at the peak of the growing season. It can be observed in Figure 12 that plot B has a more uniform pattern that closely matches the Landsat image when fused with Landsat from DOY 254. 


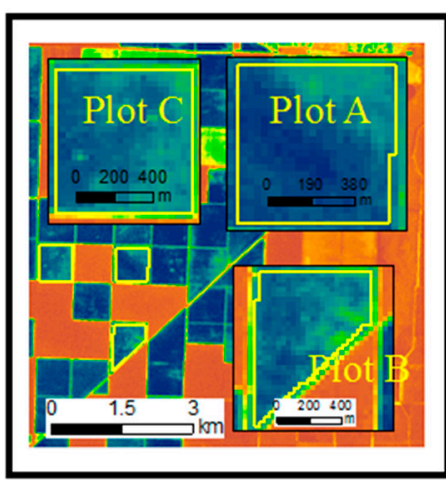

C
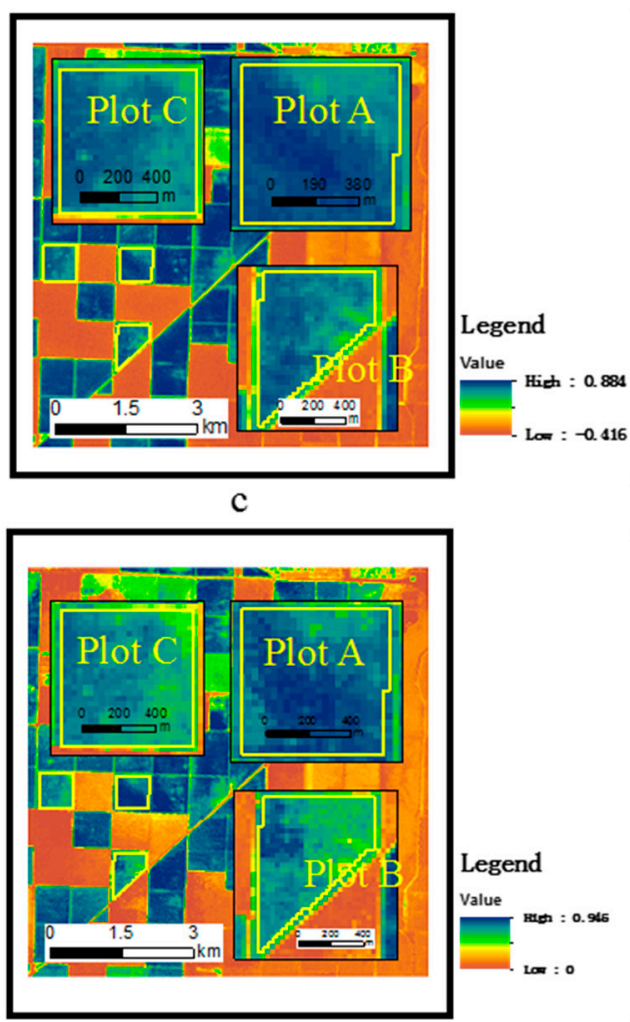

b

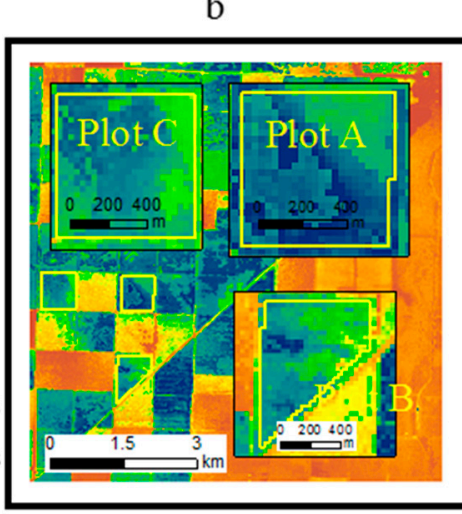

d

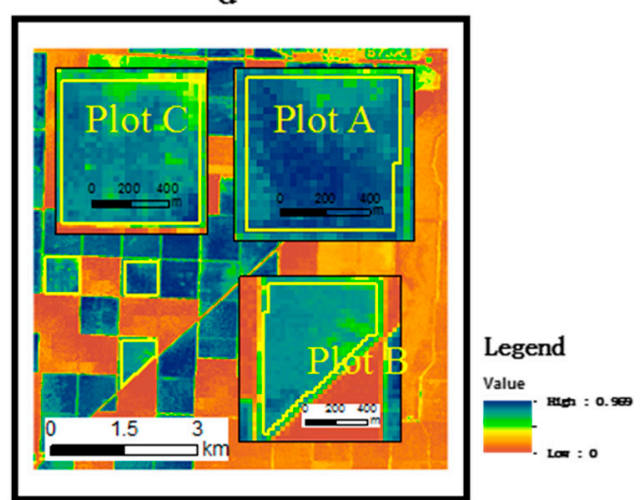

Figure 12. A visual comparison of fusion results; (a) Landsat NDVI image on DOY 230; (b-d) image on DOY 225 from fusion of MODIS 250 m imagery (NDVI ${ }_{\mathrm{F} 250 \_225}$ ) with reference Landsat images on DOY 174, DOY 206, and DOY 254.
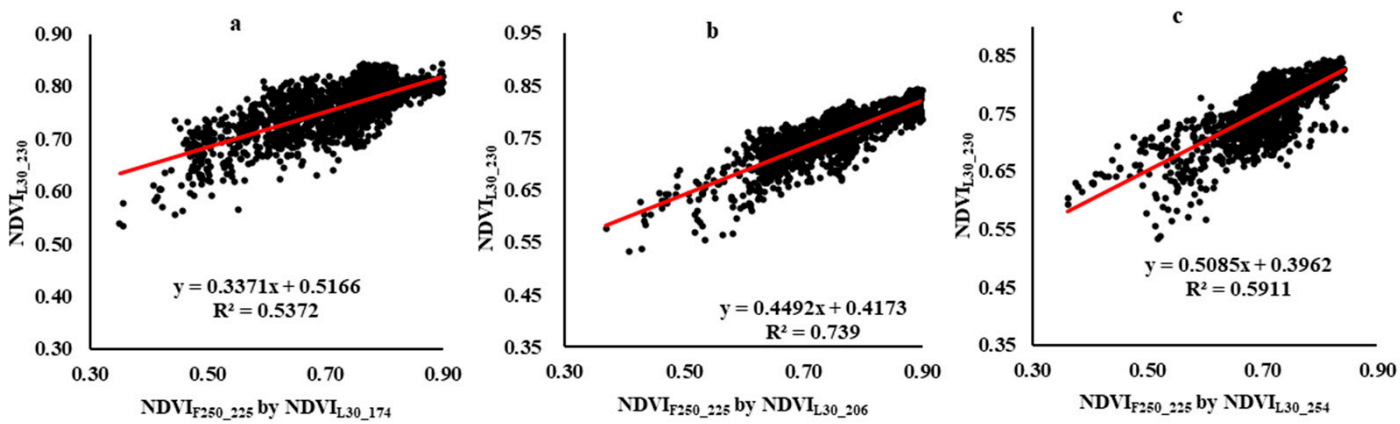

Figure 13. Scatter plots of $\mathrm{NDVI}_{\mathrm{F} 250 \_225}$ using different reference dates versus $\mathrm{NDVI}_{\mathrm{L} 30 \_230}$. NDVI $\mathrm{N}_{\mathrm{L} 30 \_230}$ versus $\mathrm{NDVI}_{\mathrm{F} 250 \_225}$ using (a) $\mathrm{NDVI}_{\mathrm{L} 30 \_174}$, (b) $\mathrm{NDVI}_{\mathrm{L} 30 \_206}$, and (c) $\mathrm{NDVI}_{\mathrm{L} 30 \_254}$ for all pixels of 3 plots).

Table 3. Results of linear regression between the fusion product $\mathrm{NDVI}_{\mathrm{F} 250 \_225}$ using different reference dates and $\mathrm{NDVI}_{\mathrm{L} 30 \_230}$ in three plots.

\begin{tabular}{cccc}
\hline Plot & Early Stage & Middle Stage & End Stage \\
\hline \multirow{2}{*}{$\mathrm{A}$} & $y=0.3669 x+0.5008$ & $y=0.6458 x+0.2429$ & $y=0.6934 x+0.253$ \\
& $\mathrm{R}^{2}=0.4933$ & $\mathrm{R}^{2}=0.831$ & $\mathrm{R}^{2}=0.6195$ \\
$\mathrm{~B}$ & $y=0.3911 x+0.4802$ & $y=0.4805 x+0.4025$ & $y=0.9684 x+0.0901$ \\
& $R^{2}=0.6298$ & $R^{2}=0.6082$ & $R^{2}=0.7703$ \\
$\mathrm{C}$ & $y=0.224 x+0.5886$ & $y=0.4911 x+0.389$ & $y=0.3436 x+0.5077$ \\
& $R^{2}=0.3148$ & $R^{2}=0.800$ & $R^{2}=0.4459$ \\
$\mathrm{ABC}$ & $y=0.3371 x+0.5166$ & $y=0.4492 x+0.4173$ & $y=0.5085 x+0.3962$ \\
& $R^{2}=0.5372$ & $R^{2}=0.739$ & $R^{2}=0.5911$ \\
\hline
\end{tabular}




\subsubsection{Analysis of Time-Series Fusion Results}

Figure 14 shows time-series curves of NDVI of Landsat, MODIS, and various fusion products. Figure 14a shows the time-series $\mathrm{NDVI}_{\mathrm{F} 500}$ using different reference Landsat images of plot A as an example, while Figure $14 \mathrm{~b}$ shows the same information for $\mathrm{NDVI}_{\mathrm{F} 250}$. The time-series $\mathrm{NDVI}_{\mathrm{F} 250}$ values display less variation and are more closely aligned with the Landsat series than the $500 \mathrm{~m}$ images, especially in the middle and end stages of the growing season.
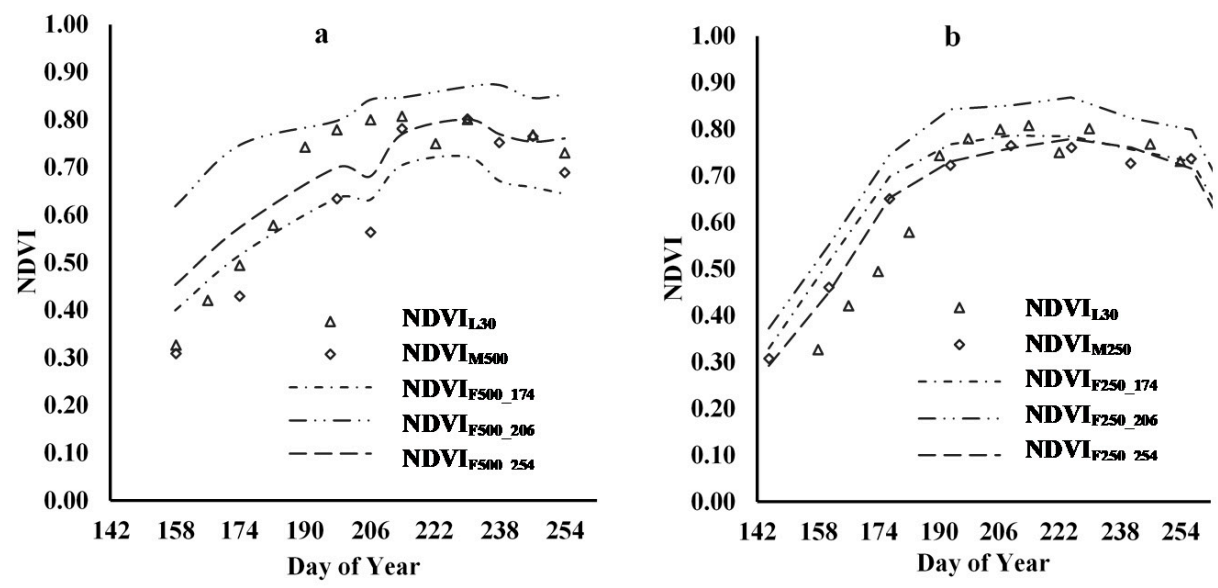

Figure 14. Time-series data of NDVI from Landsat, MODIS, and different fusion products for plot A (a) $500 \mathrm{~m}$ MOD09GA; (b) $250 \mathrm{~m}$ MOD13Q1.

Although the farm containing the study area is large, each cotton plot in our study intersected with only four to six $500 \mathrm{~m}$ MOD09GA pixels, and it appears that the mixture of cover types within these pixels caused variability and divergence from the time-series NDVI of Landsat. For the $250 \mathrm{~m}$ MOD13Q1 fusion products, the smaller pixel size appears to avoid the mixing problem to a certain extent, thereby enhancing the accuracy of fusion products generated with MOD13Q1 imagery. There are mixed pixel problems associated with all MODIS products, but the coarser the resolution, the more serious the mixing problem [39].

Based on the relationships displayed in Figure 11, which indicate that the results from fused $\mathrm{NDVI}_{\mathrm{M} 250}$ are more closely aligned with Landsat results, we selected the $250 \mathrm{~m}$ products for further detailed yield analysis. Figure 15 shows the time-series of $\mathrm{NDVI}_{\mathrm{F} 250}$ fused with $\mathrm{NDVI}_{\mathrm{L} 30 \_174}, \mathrm{NDVI}_{\mathrm{L} 30 \_206}$, and $\mathrm{NDVI}_{\mathrm{L} 30 \_254}$ for the three study plots. Comparing Figure 15 with Figure $8 \mathrm{a}$, it can be seen that the predicted fusion results are consistent with the actual Landsat time-series NDVI, with little difference among the three plots or different reference dates.
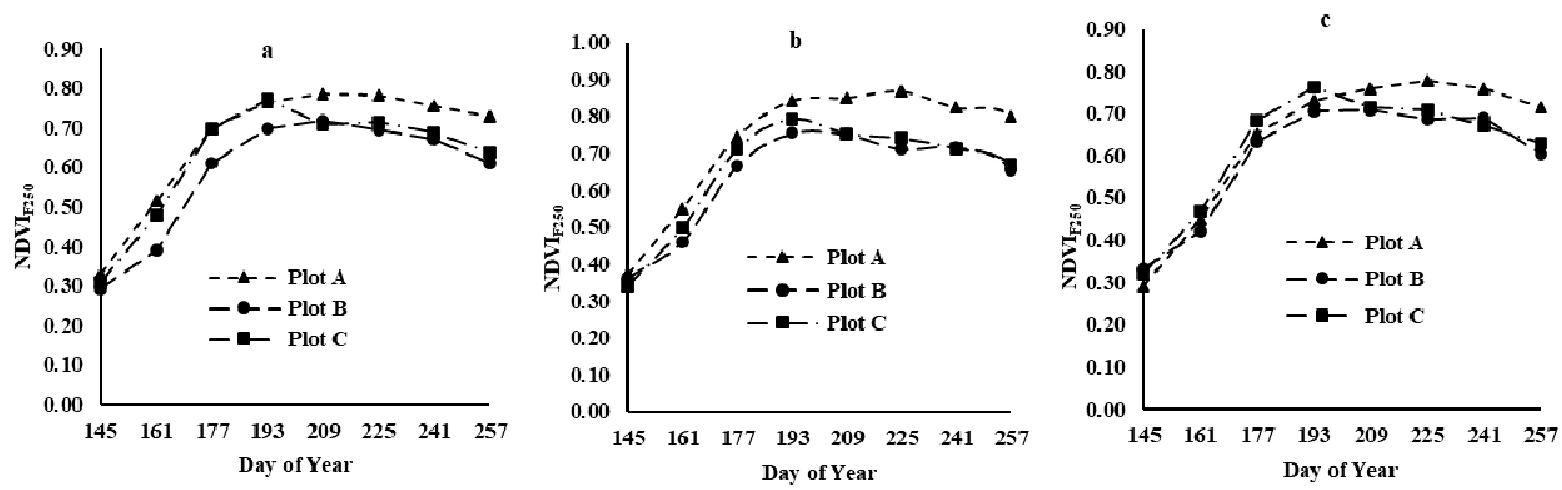

Figure 15. Time-series $\mathrm{NDVI}_{\mathrm{F} 250}$ fused with $\mathrm{NDVI}_{\mathrm{L} 30}$ of the three plots (a) fused with $\mathrm{NDVI}_{\mathrm{L} 30 \_174}$; (b) fused with NDVI $L 30 \_206 ;$ (c) fused with $\mathrm{NDVI}_{\mathrm{L} 30 \_254}$. 


\subsection{Correlation Analysis between Cotton Yield and Time-Series Fusion NDVI}

The correlation coefficients between time-series NDVI from different image products and cotton yield are shown in Figure 16. Figure 16a shows the correlation coefficients of $\mathrm{NDVI}_{\mathrm{L} 30}$ and $\mathrm{NDVI}_{\mathrm{F} 250}$ using three different fusion reference dates for all pixels in all three plots. The data show a strong correlation between $\mathrm{NDVI}_{\mathrm{L}}$ and yield for all image dates, and a similarly close relationship (except early in the season) between yield and $\mathrm{NDVI}_{\mathrm{F} 250}$ using Landsat on DOY 206. Both NDVI $\mathrm{F}_{\mathrm{F} 250}$ using Landsat on DOY 174 and $\mathrm{NDVI}_{\mathrm{F} 250}$ using Landsat on DOY 254 display considerably lower and divergent trends in correlation with yield. Figure $16 \mathrm{~b}$ shows the correlation coefficients between cotton yield and $\mathrm{NDVI}_{\mathrm{F} 250}$ using Landsat $\mathrm{NDVI}_{\mathrm{L} 30 \_206}$ as a reference for each of the three plots. As shown in Table 3, this fusion product has high accuracy with respect to duplicating Landsat values at the peak of the season, and the result is a good correlation (above 0.6 ) with yield in all three plots. There are anomalies at the start of the season in plot $C$ and at the end of the season in plot $B$, which may be explained by the fact that cotton growth during the start of the season in plot $C$ was a little worse than plot $A$ and $B$. However, plot $B$ had poor growth at the end of the season. There is a strong correlation between cotton yield and both time-series $\mathrm{NDVI}_{\mathrm{L} 30}$ and $\mathrm{NDVI}_{\mathrm{F} 250}$, and the fusion results from DOY 206 as reference using 'Middle Stage' imagery are best for all three plots (Table 3).
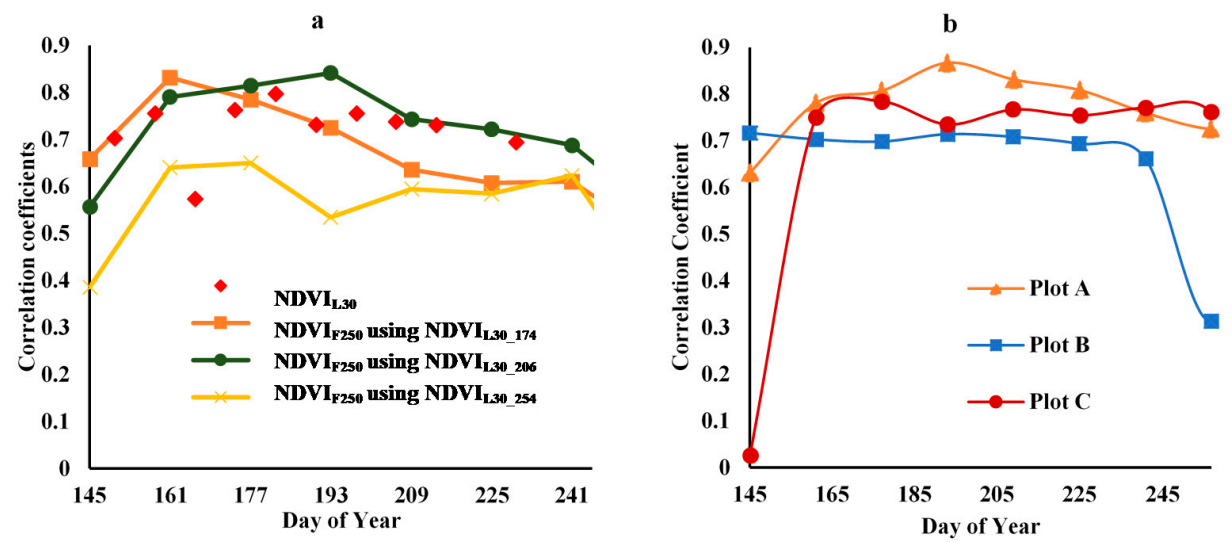

Figure 16. Correlation coefficients between $\mathrm{NDVI}_{\mathrm{L} 30}, \mathrm{NDVI}_{\mathrm{F} 250}$ fused with 3 dates of Landsat (DOY174, 206, 254) and cotton yield (a) correlation coefficient results from $\mathrm{NDVI}_{\mathrm{F} 250}$ for three plots; (b) correlation coefficient results from MOD13Q1 and Landsat $\mathrm{NDVI}_{\mathrm{L} 30 \_206}$ of three plots.

The Scatter diagram between fusion result and cotton yield for three plots is shown in Figure 17. It shows the $\mathrm{R}^{2}$ and RMSE had a high accuracy on fusion results based on NDVI F250_225 $_{\text {by NDVI }}$ L30_206, with the RMSE $14.73 \%$ and $17.26 \%$ higher than that from $\mathrm{NDVI}_{\mathrm{L} 30 \_174}$ and $\mathrm{NDVI}_{\mathrm{L} 30 \_254}$. In addition, the time-series NDVI (Figure 14) and the correlation coefficients (Figure 16) indicate that when the prediction date (t2) is closer to the date of the input Landsat image for the fusion model (t1), the fusion results are more accurate.
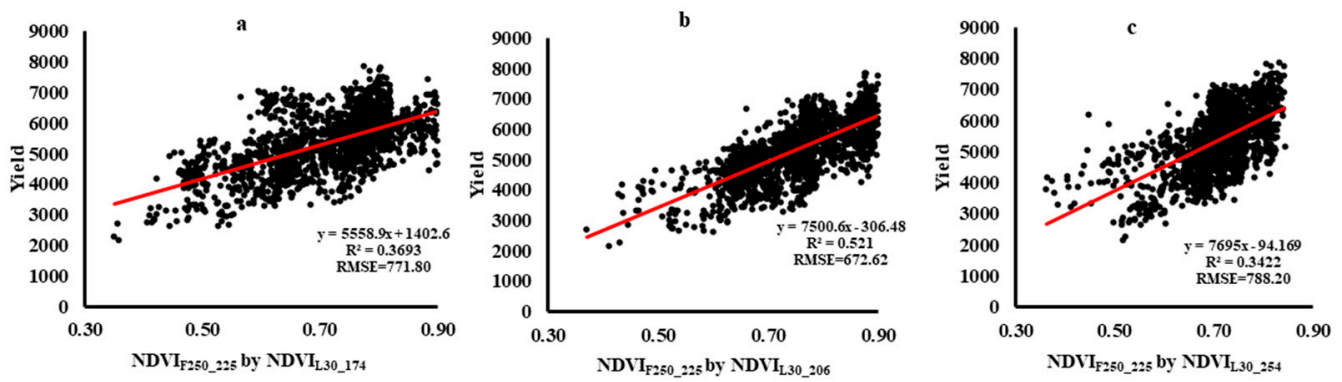

Figure 17. Scatter diagram between fusion result and cotton yield for three plots (a) NDVI $\mathrm{F}_{250 \_225}$ by $\mathrm{NDVI}_{\mathrm{L} 30 \_174}$; (b) $\mathrm{NDVI}_{\mathrm{F} 250 \_225}$ by $\mathrm{NDVI}_{\mathrm{L} 30 \_206}$; (c) $\mathrm{NDVI}_{\mathrm{F} 250 \_225}$ by $\mathrm{NDVI}_{\mathrm{L} 30 \_254}$. 


\section{Discussion}

In this study, we analyzed the impact of different reference dates on the ability of fusion results to represent the peak of the growing season. We selected MOD09GA and MOD13Q1 products to blend with Landsat data using the FSDAF model, and found that peak NDVI from the fusion of both MODIS products is influenced by the date of the Landsat images used as reference. Specifically, the fusion result for DOY 230 in the middle of the growing season using Landsat from DOY 206 as reference follows the Landsat NDVI pattern for DOY 230 with higher accuracy than the fusion products using Landsat from DOY 174 (early season) or DOY 254 (late season) as reference images. Compared to the study of Jamshidi et al. [40], it also takes into account the results of reference image fusion in different input periods for evapotranspiration. The optimal fusion results were in the early growing stage and harvest time, which is different from this study. We obtained better fusion accuracy on the middle stage of cotton growth because the crop grows well and the plots are uniform. Additionally, the soil, meteorological conditions, and environmental impact are small for remote sensing images and crop conditions. We also determined that the higher accuracy of a fused $250 \mathrm{~m}$ MODIS image can lead to a very high level of yield correlation $\left(R^{2}=0.83\right)$ than a fused $500 \mathrm{~m}$ MODIS image, indicating that the $250 \mathrm{~m}$ MOD13Q1 product with the higher spatial resolution is preferable for use in fusion models destined for field-level yield estimation. We might not achieve good accuracy with MOD09GA due to the negative effect of mixed pixels, as outlined in other studies [23,41]. With respect to the three plots, the $250 \mathrm{~m}$ fusion results are consistent, with the accuracy of fused images using a reference Landsat image from the middle of the season being highest, and accuracy for plot $\mathrm{A}$ being higher than for plot $\mathrm{B}$ or $\mathrm{C}$. We attribute the higher accuracy for plot $\mathrm{A}$ to be due to the fact that the pixel boundaries align closely with the plot boundaries, resulting in more pure pixels. Additionally, the MDI also shows the same results that MDI plot A for $250 \mathrm{~m}$ is higher than for plot B or C. For $500 \mathrm{~m}$, there are strong correlation between fusion results and MDI. However, MDI and fusion results are not relevant in fusion results of $250 \mathrm{~m}$ among plot $B$ and $C$. The two plots have serious mixed pixel problem, but because of the irregular shape of $B$, resulting in a small number of mixed cells, resulting $B<C(M D I)$. However, compared at the $30 \mathrm{~m}$ scale for fusion results, plot $C$ obtained a better accuracy than $\mathrm{B}$.

At this scale there can be problems associated with mixed pixels in all MODIS products, but it appears that the chance alignment of pixels with field boundaries can have a positive impact on accuracy. It is noteworthy that the accuracy of yield estimation in plot B using a late-season reference image $\left(R^{2}=0.77\right)$ is higher than for the mid-season reference image and only slightly lower than the highest accuracies (using mid-season imagery) in plots A and $\mathrm{C}$. This result needs further study.

In this paper, not only the number of pixels and the proportion of distribution of two MODIS products but also NDVI Pro was considered, and the MDI was constructed to analyze the fusion results. At the field scale, MDI is important for the fusion study because of the mixed pixel problems in MODIS products. Additionally, more fusion models and multi-source RS images should be tested to verify it. This study represents considerable progress in the evaluation of crops from regional land use to the field scale, and the factors affecting the application accuracy at the field scale include the differences in plot shape and surrounding crop type. In the future, the mixed pixel problem of MODIS products should be considered in the development of the fusion model at the field scale.

The data fusion model considers all plots as homogeneous farmland. However, crop type must be considered for crop yield estimation, and the crop type of one plot can differ from that of another plot. Therefore, the data fusion model maintains the overall spatiotemporal crop and land cover patterns but cannot obtain adequate results in areas with different crop phenology or small plots. A yield estimation model for different crops and different crop phenology will be considered in the future. Although currently there are a number of higher resolution satellite sensors such as Sentinel-2 available [42], we restricted our study to older imagery due to the availability of time-series Landsat 
data and high-resolution yield data at this time at this site, but it is a benefit to temporal change studies of a methodology for generating historical high-resolution field-level yield estimates.

\section{Conclusions}

In this study, we extended the application of data fusion to the field scale to estimate crop yields. Additionally, we analyzed time-series Landsat and MODIS NDVI data and assessed the importance of different Landsat reference date for fusion results. First, this study found that the $\mathrm{NDVI}_{\mathrm{F}}$ from the fusion data is significantly influenced by the dates of the Landsat images during the cotton growing season. Second, the fusion result and the yield estimation model from MOD13Q1 and Landsat TM5 are more accurate than those of MOD09GA and Landsat, which proves that the $250 \mathrm{~m}$ MOD13Q1 product with the higher spatial resolution is preferable for use in fusion models rather than the $500 \mathrm{~m}$ MOD09GA product. Third, yield estimation model accuracy was influenced by the MDI of the three plots, the number of pixels, and the proportion of distribution of two MODIS products. The $\mathrm{NDVI}_{\text {Pro }}$ can influence the fusion results at $250 \mathrm{~m}$ and $500 \mathrm{~m}$ spatial resolutions. This study estimates crop yields using fusion images from the MOD13Q1 product at the field scale; these images can be used for vegetation monitoring and yield prediction with RS at the field scale.

Despite the success of fusion study at the field level, there are additional areas that need study; (1) in future research, Sentinel-2 and Landsat images could be combined to improve the spatial and temporal resolution and enable a more precise estimation of crop yield. (2) In addition to NDVI, the Enhanced Vegetation Index (EVI) could be an alternative for densely vegetated areas. EVI has been shown to provide a high degree of separation of vegetative reflection and could enhance yield estimation results. In our next study, we will test MODIS EVI in the FSDAF model and evaluate the accuracy.

Author Contributions: Data curation, L.M. and X.Z.; formal analysis, L.M. and X.Z.; funding acquisition, H.L.; methodology, L.M.; resources, S.L.U.; software, L.M.; writing-original draft, L.M.; writing-review and editing, H.L. All authors have read and agreed to the published version of the manuscript.

Funding: This research was supported by the National Natural Science Foundation of China (41671438), the Talent Recruitment project of Northeast Institute of Geography and Agroecology, Chinese Academy of Sciences.

Acknowledgments: We thank Xiaolin Zhu for the FSDAF code and Ted Huffman (retired) form Agriculture and Agri-Food Canada for providing presentation and linguistic assistance during manuscript revision.

Conflicts of Interest: The authors declare no conflict of interest.

\section{References}

1. Shen, M.; Tang, Y.; Chen, J.; Zhu, X.; Zheng, Y. Influences of temperature and precipitation before the growing season on spring phenology in grasslands of the central and eastern Qinghai-Tibetan Plateau. Agric. For. Meteorol. 2011, 151, 1711-1722. [CrossRef]

2. Shen, M.; Zhang, G.; Cong, N.; Wang, S.; Kong, W.; Piao, S. Increasing altitudinal gradient of spring vegetation phenology during the last decade on the qinghai-tibetan plateau. Agric. For. Meteorol. 2014, 189-190, 71-80. [CrossRef]

3. Kibret, K.S.; Marohn, C.; Cadisch, G. Assessment of land use and land cover change in South Central Ethiopia during four decades based on integrated analysis of multi-temporal images and geospatial vector data. Remote Sens. Appl. Soc. Environ. 2016, 3, 1-19. [CrossRef]

4. Ran, Y.; Li, X.; Jin, R.; Kang, J.; Cosh, M.H. Strengths and weaknesses of temporal stability analysis for monitoring and estimating grid-mean soil moisture in a high-intensity irrigated agricultural landscape. Water Resour. Res. 2017, 53, 283-301. [CrossRef]

5. Nuarsa, I.W.; Nishio, F.; Hongo, C.; Mahardika, I.G. Using variance analysis of multitemporal MODIS images for rice field mapping in Bali Province, Indonesia. Int. J. Remote Sens. 2012, 33, 5402-5417. [CrossRef]

6. Sakamoto, T.; Gitelson, A.A.; Arkebauer, T.J. MODIS-based corn grain yield estimation model incorporating crop phenology information. Remote Sens. Environ. 2013, 131, 215-231. [CrossRef]

7. Zhang, Z.; Li, Z.; Chen, Y.; Zhang, L.; Tao, F. Improving regional wheat yields estimations by multi-step-assimilating of a crop model with multi-source data. Agric. For. Meteorol. 2020, 290, 107993. [CrossRef] 
8. Yuhan, R.; Xiaolin, Z.; Jin, C.; Jianmin, W. An improved method for producing high spatial-resolution ndvi time series datasets with multi-temporal modis ndvi data and landsat tm/etm+ images. Remote Sens. 2015, 7, 7865-7891.

9. Yu, L.; Shi, Y.; Gong, P. Land cover mapping and data availability in critical terrestrial ecoregions: A global perspective with Landsat thematic mapper and enhanced thematic mapper plus data. Biol. Conserv. 2015, 190, 34-42. [CrossRef]

10. Masek, J.G.; Huang, C.; Wolfe, R.; Cohen, W.; Hall, F.; Kutler, J.; Nelson, P. North american forest disturbance mapped from a decadal landsat record. Remote Sens. Environ. 2008, 112, 2914-2926. [CrossRef]

11. Main-Knorn, M.; Cohen, W.B.; Kennedy, R.E.; Grodzki, W.; Pflugmacher, D.; Griffiths, P.; Hostert, P. Monitoring coniferous forest biomass change using a Landsat trajectory-based approach. Remote Sens. Environ. 2013, 139, 277-290. [CrossRef]

12. Cohen, W.B.; Goward, S.N. Landsat's role in ecological applications of remote sensing. BioScience 2004, 54, 535-545. [CrossRef]

13. Roy, D.P.; Ju, J.; Lewis, P.; Schaaf, C.; Lindquist, E. Multi-temporal modis-landsat data fusion for relative ra-diometric normalization, gap filling, and prediction of landsat data. Remote Sens. Environ. 2008, 112, 3112-3130. [CrossRef]

14. González-Sanpedro, M.; Le Toan, T.; Moreno, J.; Kergoat, L.; Rubio, E. Seasonal variations of leaf area index of agricultural fields retrieved from Landsat data. Remote Sens. Environ. 2008, 112, 810-824. [CrossRef]

15. Minghelli, A.; Chevalier, C.; Descloitres, J.; Berline, L.; Blanc, P.; Chami, M. Synergy between Low Earth Orbit (LEO)—MODIS and Geostationary Earth Orbit (GEO)_GOES Sensors for Sargassum Monitoring in the Atlantic Ocean. Remote. Sens. 2021, 13, 1444. [CrossRef]

16. Yang, J.J.; Wang, B.Y.; Shi, Y.; Li, P.; Zhang, E.W. A multi-sensors weighted data fusion method based on measurement traversal correction. J. Phys. Conf. Ser. 2021, 1846, 012081. [CrossRef]

17. Gao, F.; Masek, J.; Schwaller, M.; Hall, F. On the blending of the Landsat and MODIS surface reflectance: Predicting daily Landsat surface reflectance. IEEE Trans. Geosci. Remote Sens. 2006, 44, 2207-2218.

18. Zhu, X.; Chen, J.; Gao, F.; Chen, X.; Masek, J.G. An enhanced spatial and temporal adaptive reflectance fusion model for complex heterogeneous regions. Remote Sens. Environ. 2010, 114, 2610-2623. [CrossRef]

19. Hilker, T.; Wulder, M.; Coops, N.; Linke, J.; McDermid, G.; Masek, J.G.; Gao, F.; White, J. A new data fusion model for high spatialand temporal-resolution mapping of forest disturbance based on Landsat and MODIS. Remote Sens. Environ. 2009, 113, $1613-1627$. [CrossRef]

20. Emelyanova, I.V.; McVicar, T.R.; Van Niel, T.G.; Li, L.T.; Van Dijk, A.I.J.M. Assessing the accuracy of blending Landsat-MODIS surface reflectances in two landscapes with contrasting spatial and temporal dynamics: A framework for algorithm selection. Remote Sens. Environ. 2013, 133, 193-209. [CrossRef]

21. Zhu, X.; Helmer, E.H.; Gao, F.; Liu, D.S.; Chen, J.; Lefsky, M.A. A flexible spatiotemporal method for fusing satellite images with different resolutions. Remote Sens. Environ. 2016, 172, 165-177. [CrossRef]

22. Broich, M.; Huete, A.; Tulbure, M.G.; Ma, X.; Xin, Q.; Paget, M.; Restrepo-Coupe, N.; Davies, K.; Devadas, R.; Held, A. Land surface phenological response to decadal climate variability across Australia using satellite remote sensing. Biogeosciences 2014, 11, 5181-5198. [CrossRef]

23. Ali, S.; Cheema, M.; Waqas, M.; Waseem, M.; Awan, U.; Khaliq, T. Changes in Snow Cover Dynamics over the Indus Basin: Evidences from 2008 to 2018 MODIS NDSI Trends Analysis. Remote Sens. 2020, 12, 2782. [CrossRef]

24. Xu, Q.; Yang, G.; Long, H.; Wang, L.; Li, X.; Huang, D. Crop information identification based on MODIS NDVI time-series data. Trans. Chin. Soc. Agric. Eng. 2014, 30, 134-144.

25. Alexandridis, T.; Ovakoglou, G. Relation of MODIS EVI and LAI Across Time, Vegetation Types and Hydrological Regimes. In Proceedings of the EGU General Assembly Conference, Vienna, Austria, 12-17 April 2015.

26. Liu, J.; Huffman, T.; Qian, B.; Shang, J.; Li, Q.; Dong, T.; Davidson, A.; Jing, Q. Crop yield estimation in the Canadian Prairies using Terra/MODIS-derived crop metrics. IEEE J. Sel. Top. Appl. Earth Obs. Remote Sens. 2020, 1, 99. [CrossRef]

27. Sakamoto, T. Incorporating environmental variables into a MODIS-based crop yield estimation method for United States corn and soybeans through the use of a random forest regression algorithm. ISPRS J. Photogramm. Remote. Sens. 2020, 160, 208-228. [CrossRef]

28. Son, N.; Chen, C.; Minh, V.Q.; Trung, N. A comparative analysis of multitemporal MODIS EVI and NDVI data for large-scale rice yield estimation. Agric. For. Meteorol. 2014, 197, 52-64. [CrossRef]

29. Chipanshi, A.; Zhang, Y.; Kouadio, L.; Newlands, N.; Davidson, A.; Hill, H.; Warren, R.; Qian, B.; Daneshfar, B.; Bedard, F.; et al. Evaluation of the integrated canadian crop yield fore-caster (ICCYF) model for in-season prediction of crop yield across the canadian agricultural landscape. Agric. For. Meteorol. 2015, 206, 137-150.

30. Franch, B.; Vermote, E.; Becker-Reshef, I.; Claverie, M.; Huang, J.; Zhang, J.; Justice, C.; Sobrino, J.A. Improving the timeliness of winter wheat production forecast in the United States of America, Ukraine and China using MODIS data and NCAR Growing Degree Day information. Remote Sens. Environ. 2015, 161, 131-148. [CrossRef]

31. Liu, H.; Meng, L.; Zhang, X.; Susan, U.; Ning, D.; Sun, S. Estimation model of cotton yield with time-series Landsat images. Trans. Chin. Soc. Agric. Eng. 2015, 31, 215-220.

32. Meng, L.; Zhang, X.L.; Liu, H.; Guo, D.; Yan, Y.; Qin, L.; Pan, Y. Estimation of cotton yield using the recon-structed time-series vegetation index of landsat data. Can. J. Remote Sens. 2017, 43, 244-255. [CrossRef]

33. ZarcoTejada, P.J.; Ustin, S.L.; Whiting, M.L. Temporal and Spatial Relationships between Within-Field Yield Variability in Cotton and High-Spatial Hyperspectral Remote Sensing Imagery. Agron. J. 2005, 97, 641-653. [CrossRef] 
34. Meng, L.; Liu, H.; Zhang, X.; Ren, C.; Ustin, S.; Qiu, Z.; Xu, M.; Guo, D. Assessment of the effectiveness of spatiotemporal fusion of multi-source satellite images for cotton yield estimation. Comput. Electron. Agric. 2019, 162, 44-52. [CrossRef]

35. Bookstein, F.L. Shape and the information in medical images: A decade of the morphometric synthesis. In Workshop on Mathematical Methods in Biomedical Image Analysis; IEEE: San Francisco, CA, USA, 1997.

36. Rojas, O. Operational maize yield model development and validation based on remote sensing and agrometeorological data in Kenya. Int. J. Remote Sens. 2007, 28, 3775-3793. [CrossRef]

37. Dehghani, R.; Ghorbani, M.A.; Teshnehlab, M.; Rikhtehgar, G.A.; Asadi, E. Comparison and evalution of bayesian neural network, gene gramming, support vector machine and multiple expression proLinear regression in river discharge estimation (Case Study: Sufi Chay Basin). Iran. Irrig. E Water Eng. 2015, 5, 66-85.

38. Fitzgerald, G.J.; Pinter, P.J., Jr.; Hunsaker, D.J.; Clarke, T.R. Multiple shadow fractions in spectral mixture analysis of a cotton canopy. Remote Sens. Environ. 2005, 97, 526-539. [CrossRef]

39. Chen, J.; Jnsson, P.M. A simple Method for Reconstructing a High Quality NDVI Time-series Data Set Based on the Savitzky-Golay Filter. Remote Sens. Environ. 2004, 91, 332. [CrossRef]

40. Jamshidi, S.; Zand-Parsa, S.; Jahromi, M.N.; Niyogi, D. Application of A Simple Landsat-MODIS Fusion Model to Estimate Evapotranspiration over A Heterogeneous Sparse Vegetation Region. Remote Sens. 2019, 11, 741. [CrossRef]

41. Sakamoto, T.; Yokozawa, M.; Toritani, H.; Shibayama, M.; Ishitsuka, N.; Ohno, H. A crop phenology detection method using time-series modis data. Remote Sens. Environ. 2005, 96, 366-374. [CrossRef]

42. Zhou, X.; Wang, P.; Tansey, K.; Zhang, S.; Wang, L. Developing a fused vegetation temperature condition index for drought monitoring at field scales using sentinel-2 and modis imagery. Comput. Electron. Agric. 2020, 168, 105144. [CrossRef] 